Linköping Studies in Science and Technology.

Dissertations No. 1706

\title{
Static and Fatigue Failure of Bolted Joints in Hybrid Composite-Aluminium Aircraft Structures
}

\section{Zlatan Kapidžić}

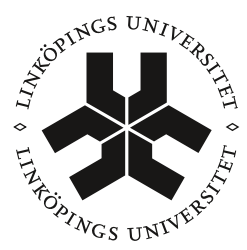

\section{Linköping University}

\author{
Division of Solid Mechanics \\ Department of Management and Engineering \\ Linköping University \\ SE-581 83, Linköping, Sweden
}

Linköping, December 2015 
Printed by:

LiU-Tryck, Linköping, Sweden, 2015

ISBN 978-91-7685-942-1

ISSN 0345-7524

Distributed by:

Linköping University

Department of Management and Engineering

SE-581 83, Linköping, Sweden

\section{(c) 2015 Zlatan Kapidžić}

This document was prepared with $\mathrm{HT}_{\mathrm{E}} \mathrm{X}$, October 27, 2015

No part of this publication may be reproduced, stored in a retrieval system, or be transmitted, in any form or by any means, electronic, mechanical, photocopying, recording, or otherwise, without prior permission of the author. 


\section{Preface}

The work presented in this dissertation has been carried out at Saab AB and at the Division of Solid Mechanics, Linköping University. The work has been performed within the projects HYBRIS - Optimalt utnyttjande av avancerade strukturmaterial $i$ hybrida skrovkonstruktioner, funded by Swedish Defence Materiel Administration (FMV) and NFFP6: Structural assessment of hybrid assemblages, funded by the Swedish Armed Forces, Swedish Defence Materiel Administration and Swedish Governmental Agency for Innovation Systems.

First, I would like to thank my supervisors, Prof. Hans Ansell (Saab AB), Prof. Kjell Simonsson and Prof. Larsgunnar Nilsson, for all their support and guidance during the course of this work. For valuable discussions and comments on my work I would like to thank all my colleagues within the HYBRIS and NFFP6 projects and in particular M.Sc. Anders Bredberg (Saab AB) and Dr. Joakim Schön (FOI, Swedish Defence Research Agency). Also, I would like to thank all my colleagues at Saab AB and Linköping University for their help, encouragement and interesting discussions.

I am also grateful to my family and all my friends for their support. Especially, I would like to thank my dear Karin and my sons Adrian and Edvin for their patience and daily encouragement.

Linköping, December 2015

Zlatan Kapidžić 



\section{Abstract}

The use of fibre composites in the design of load carrying aircraft structures has been increasing over the last few decades. At the same time, aluminium alloys are still present in many structural parts, which has led to an increase of the number of hybrid composite-aluminium structures. Often, these materials are joined at their interface by bolted connections. Due to their different response to thermal, mechanical and environmental impact, the composite and the aluminium alloy parts are subject to different design and certification practices and are therefore considered separately. The current methodologies used in the aircraft industry lack well-developed methods to account for the effects of the mismatch of material properties at the interface. One such effect is the thermally induced load which arises at elevated temperature due to the different thermal expansion properties of the constituent materials. With a growing number of hybrid structures, these matters need to be addressed.

The rapid growth of computational power and development of simulation tools in recent years have made it possible to evaluate the material and structural response of hybrid structures without having to entirely rely on complex and expensive testing procedures. However, as the failure process of composite materials is not entirely understood, further research efforts are needed in order to develop reliable material models for the existing simulation tools.

The work presented in this dissertation involves modelling and testing of bolted joints in hybrid composite-aluminium structures. The main focus is directed towards understanding the failure behaviour of the composite material under static and fatigue loading, and how to include this behaviour in large scale models of a typical bolted airframe structure in an efficient way. In addition to that, the influence of thermally induced loads on the strength and fatigue life is evaluated in order to establish a design strategy that can be used in the industrial context.

The dissertation is divided into two parts. In the first one, the background and the theory are presented while the second one consists of five scientific papers. 



\section{Sammanfattning}

Andelen fiberkomposit som används i lastbärande flygplansstrukturer växer ständigt, samtidigt som aluminiumlegeringar fortfarande används i stor omfattning. Detta har lett till en ökning av antal hybrida konstruktioner bestående av komposit och aluminium. Komponenterna i dessa konstruktioner sammanfogas ofta med bultförband. Komposit och aluminium uppvisar olika egenskaper när de utsätts för termisk, mekanisk och miljöbaserad påverkan, vilket är anledningen till att de hanteras separat och enligt olika regler i design och certifieringsprocesser. Nuvarande metodik i flygplansindustrin hanterar inte effekter av samverkan mellan de olika materialen, såsom termiskt inducerade laster som uppstår på grund av olika benägenhet till temperaturutvidgning, vilket leder till att hybrida strukturer ibland diskvalificeras som ett alternativ. Ökande antal blandstrukturer kräver dock att metodiken utvecklas till att omfatta även dessa fall.

Den snabba utvecklingen inom beräknings och simuleringstekniken de senaste åren har gjort det möjligt att, med hjälp av olika simuleringsverktyg, utvärdera material och strukturbeteende utan att behöva förlita sig på dyrbar och komplex provning i samma omfattning som tidigare. Problemet är dock att den komplexa skade och brottprocessen som äger rum i kompositmaterial inte är fullständigt förstådd. Ytterligare forskningsinsatser krävs för att utveckla tillförlitliga materialmodeller för implementering i befintliga simuleringsverktyg.

I detta avhandlingsarbete ingår modellering och provning av bultförband i hybrida komposit-aluminium strukturer. Fokus ligger på att förstå brottbeteendet i kompositen i bultförbandet under statisk och cyklisk belastning, samt hur detta kan, på ett effektivt sätt, modelleras och inkluderas i större modeller av typiska skrovkonstruktioner. Utöver det, studeras inverkan av termiskt inducerade laster på kompositens hållfasthet och utmattningslivslängd. Resultaten ligger till grund för en designstrategi som kan användas i industriella sammanhang.

Avhandlingen består av två delar. Den första sammanfattar bakgrunden och teorin och den andra innehåller fem vetenskapliga artiklar. 



\section{List of Papers}

The following papers have been appended to this thesis:

I. Z. Kapidžić, L. Nilsson, H. Ansell, (2014), Conceptual studies of a compositealuminum hybrid wing box demonstrator, Aerospace Science and Technology, Volume 32, Issue 1, pp. 42-50, 2014.

II. Z. Kapidžić, L. Nilsson, H. Ansell, (2014), Finite element modeling of mechanically fastened composite-aluminum joints in aircraft structures, Composite Structures, Volume 109, pp. 198-210, 2014.

III. Z. Kapidžić, H. Ansell, J. Schön, K. Simonsson (2015), Quasi-static bearing failure of CFRP composite in biaxially loaded bolted joints, Composite Structures, Volume 125, pp. 60-71, 2015.

IV. Z. Kapidžić, H. Ansell, J. Schön, K. Simonsson (2015), Fatigue bearing failure of CFRP composite in biaxially loaded bolted joints at elevated temperature, Composite Structures, Volume 127, pp. 298-307, 2015.

V. Z. Kapidžić, H. Ansell, J. Schön, K. Simonsson (2015), Fatigue bearing failure of CFRP composite in bolted joints exposed to biaxial variable amplitude loading at elevated temperature, Submitted.

\section{Note}

The papers have been reformatted to fit the layout and the style of the thesis.

\section{Own contribution}

The design of the experimental program performed in this thesis was a joint effort by Prof. Hans Ansell, Dr. Joakim Schön and myself. The experiments were performed by Dr. Joakim Schön. All fractography work was performed by Prof. Johan Moverare and myself. I have borne primary responsibility for all other parts of the work presented in the papers included in this thesis. 
The work in this project has also resulted in the following paper which is not included in this thesis:

I. Z. Kapidžić, H. Ansell, (2015), Fatigue bearing failure of CFRP composite in biaxially loaded bolted joints at elevated temperature, In Proceedigs of the 34th conference and the 28th symposium of the International Committee on Aeronautical Fatigue and Structural Integrity, pp. 531-541, Helsinki, June, 2015 . 


\section{Contents}

$\begin{array}{ll}\text { Preface } & \text { iii }\end{array}$

Abstract $\quad$ v

Sammanfattning vii

$\begin{array}{ll}\text { List of Papers } & \text { ix }\end{array}$

Contents $\quad$ xi

Part I - Theory and Background 1

1 Introduction 3

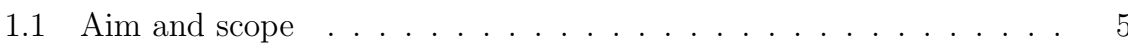

1.2 Thesis outline . . . . . . . . . . . . . . . 6

$\begin{array}{lll}2 & \text { Structural integrity assessment } & 7\end{array}$

3 Failure of CFRP composites $\quad 11$

3.1 Static failure . . . . . . . . . . . . . . . . . . . . 12

3.2 Fatigue failure . . . . . . . . . . . . . . . . 15

3.3 Bolted joints . . . . . . . . . . . . . . . . . 16

4 Experimental work $\quad 19$

4.1 Test setup . . . . . . . . . . . . . . . . . . . . . . . 19

4.2 Damage observations . . . . . . . . . . . . . . . 20

5 Material modelling $\quad 23$

5.1 Elastic behaviour ... . . . . . . . . . . . . . . . . 23

5.2 Static failure . . . . . . . . . . . . . . . . 26

$5.2 .1 \quad$ Failure initiation criteria . . . . . . . . . . . . 26

5.2 .2 Damage progression . . . . . . . . . . . . . . . . . . . . . . . . . . 31

5.3 Fatigue failure . . . . . . . . . . . . . . . . . . . 33

$6 \quad$ Finite element modelling $\quad 35$

6.1 Modelling of quasi-static failure . . . . . . . . . . . . . . 35 
6.2 Structural modelling . . . . . . . . . . . . . . . . . . . . . . 36

6.3 Fatigue failure modelling . . . . . . . . . . . . . . . . 37

$\begin{array}{lll}7 & \text { Outlook } & 39\end{array}$

8 Review of appended papers $\quad 41$

$\begin{array}{ll}\text { Bibliography } & 45\end{array}$

$\begin{array}{ll}\text { Part II - Appended papers } & 55\end{array}$

Paper I: Conceptual studies of a composite-aluminium hybrid wing box

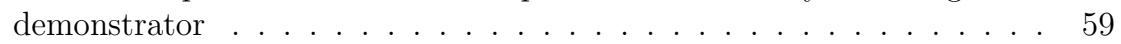

Paper II: Finite element modelling of mechanically fastened compositealuminium joints in aircraft structures . . . . . . . . . . . . . 83

Paper III: Quasi-static bearing failure of CFRP composite in biaxially loaded bolted joints . . . . . . . . . . . . . . . . . . . 113

Paper IV: Fatigue bearing failure of CFRP composite in biaxially loaded bolted joints at elevated temperature . . . . . . . . . . . . . . . 143

Paper V: Fatigue bearing failure of CFRP composite in bolted joints exposed to biaxial variable amplitude loading at elevated temperature . . 167 
Part I

Theory and Background 



\section{Introduction}

The aircraft industry has for a long time used light-weight materials in load carrying components. Primarily aluminium alloys, are extensively utilised in the airframe structural parts due to their high strength-to-weight ratio. The airworthiness, the structural integrity and the durability of aircraft structures are ensured by a structural integrity assessment procedure, which was developed over the years, [1]. It includes analytical and experimental techniques for assessing and verifying the structural behaviour, the fatigue life, the damage tolerance and the residual and static strength of the aircraft components. Naturally, theses techniques are suited for assessment of metal structures and are based on the way metals respond to thermal, mechanical and environmental influence.

The constant striving for structural weight reduction over the last decades, has led to introduction of other low-weight materials, such as fibre reinforced polymer (FRP) composites. These materials have been increasingly used in both civil and military aircraft structure. Figure 1 illustrates the the usage of FRP composites in the next generation version of the fighter aircraft Gripen.

The FRP composite materials are typically manufactured as laminate plates, where layers of fibre reinforced polymer, with different fibre orientations, are stacked onto

Carbon-Fibre Composite (CFRP)

Glass-Fibre Composite (GFRP)

Aramid-Fibre Composite (AFRP)

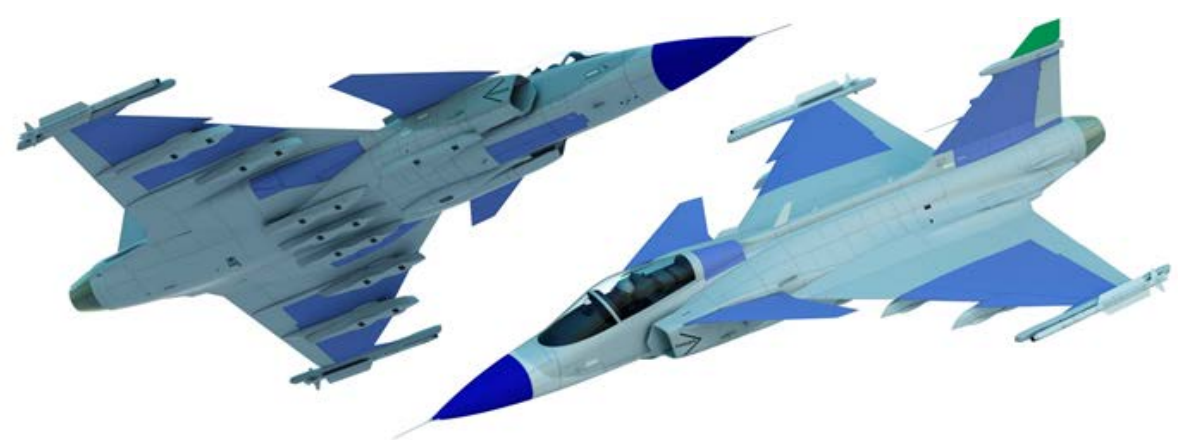

Figure 1. Composite material usage in JAS39 Gripen. 
each other. Such laminates are well-suited to be used for wing skins and other thin-walled, in-plane loaded components in the aircraft. Another advantage is that the layup sequence of the laminate can be tailored to fit different requirements of stiffness and strength. The drawback with FRP laminates is that they have low outof-plane strength and are sensitive to impact and to thermal and environmental influence. Also, they fail due to multiple damage mechanisms and show large scatter in their material properties which makes the failure modes of large-scale structures difficult to predict [2]. These circumstances make the analytical and experimental techniques developed for metals unsuitable for FRP laminates, which is why other methods had to be developed for composites. It can be added that, due to their complexity, the damage and fatigue mechanisms in composites are still not fully understood, which is why most of the failure theories and prediction models are deficient.

In recent years, there has been a rapid development of computational power and numerical simulation tools that allow for modelling of large structures, as well as local detailed problems, such as material failure and joints. Especially theories adapted for metals, such as the plasticity theory [3-6] and the fracture mechanics theory $[7,8]$ are well-established within simulation software. Failure theories for composite materials [9-13], and particularly fatigue failure [14-16], have not been introduced in the same extent, partly due to the complexity of the damage mechanisms. Further research efforts are therefore needed in order to develop an understanding of the failure process from which useful theories can be derived.

Since aluminium alloys are still present in many structural parts, the number of hybrid composite-aluminium structures has also been increasing. The components made of the different materials are commonly assembled using bolted joints. In such mixed structures, problems may arise related to the incompatibility of the material properties at the interface and the discrepancies in the techniques used to assess each material type. With a growing number of hybrid structures, these issues need to be addressed.

One such issue is the thermally induced stress that arises in hybrid structures at elevated temperature, due to the difference in thermal expansion properties of composite and aluminium. The aluminium tends to expand while being restrained by the composite, which results in stresses. In large bolted structures, the thermally induced stresses can be of significant magnitude even at relatively low temperature differences and should therefore be accounted for. However, it is unclear how the presence of the thermally induced loads affects the local failure behaviour of the bolted joint.

The thermal expansion problem can be simulated with numerical methods but testing of large structures at elevated temperature is a very complicated matter. Numerical simulation of failure in structures including a large number of bolted connections is a challenge in itself. Detailed modelling of each fastener, especially including failure, results in computationally very extensive analyses. Simplified methods are therefore needed. 


\subsection{Aim and scope}

The main focus of this research is directed towards understanding and modelling of the failure behaviour of the composite under static and fatigue loading in hybrid, shear loaded bolted structures. The work includes experimental testing of joints at elevated temperature and modelling of composite material behaviour in the joints, both on local specimen level and in a large-scale hybrid structure. In addition to that, the influence of thermally induced loads on the strength and fatigue life is evaluated in order to establish the basis for a design strategy that can be applied in the industrial context.

The work has been performed within two industrial research projects. The first project, HYBRIS - Optimalt utnyttjande av avancerade strukturmaterial i hybrida skrovkonstruktioner, includes testing at elevated temperature and analyses of a hybrid wing-like box structure, see Fig. 2, with carbon fibre reinforced polymer (CFRP) skins and aluminium inner structure. In Paper I, a conceptual study of different hybrid design solutions and design requirements was performed and in Paper II the failure of bolted connections in the box was modelled and analysed using the Finite Element Method (FEM). The testing activities are ongoing and are not discussed in this thesis.
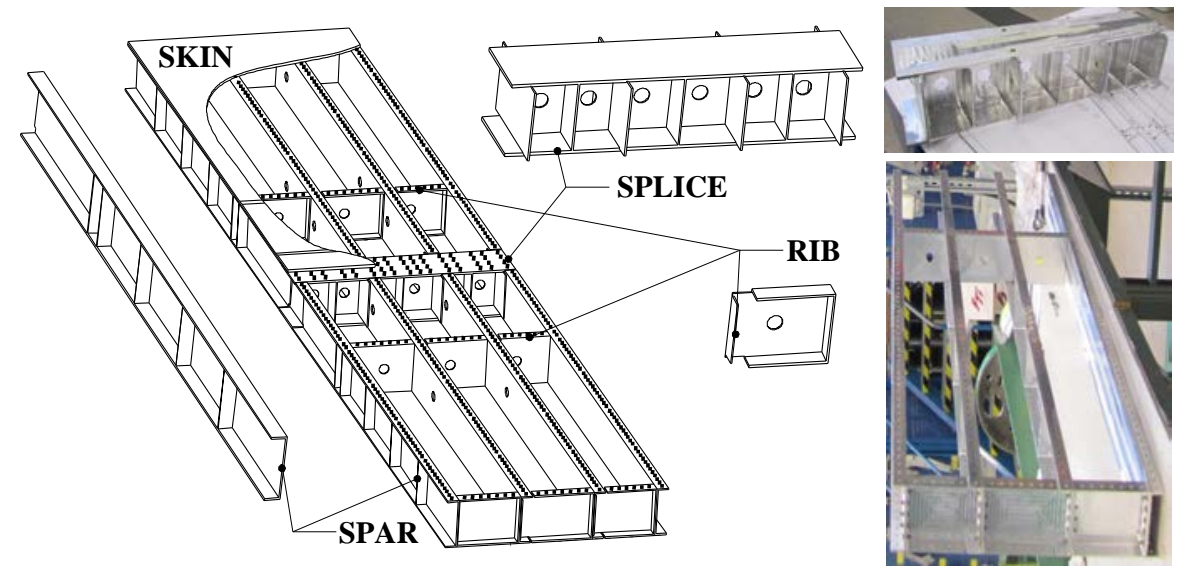

Figure 2. Hybrid wing-like box structure, with CFRP skin and aluminium splice, ribs and spars, used in the HYBRIS project, dimensions 3300x630x150 mm.

In the second project, NFFP6: Structural assessment of hybrid assemblages, local bearing failure of the CFRP composite in hybrid bolted joint specimens at elevated temperature, including thermally induced loads, is studied by testing and analyses. Modelling of quasi-static failure is treated in Paper III, while Paper IV concerns constant amplitude fatigue failure and Paper $\mathbf{V}$ deals with failure in spectrum loading. 


\subsection{Thesis outline}

This dissertation is partly based on my Licentiate of Engineering thesis Strength analysis and modeling of hybrid composite-aluminium aircraft structures from 2013. In Chapter 2, a discussion is presented regarding the issues of the aircraft structural integrity assessment procedure for hybrid composite-aluminium structures. Chapter 3 briefly describes the characteristics of CFRP composites with emphasis on damage development and failure mechanisms. In Chapter 4, the experimental work is presented. Modelling of composite material behaviour is discussed in Chapter 5 and in Chapter 6 some aspects of the numerical modelling of bolted joints and structures are discussed. In Chapter 7, future research topics are outlined and in Chapter 8 a review of the appended papers is made. 


\section{Structural integrity assessment}

The structural integrity assessment procedure considers a large number of engineering aspects and covers the whole life span of the aircraft, from concept to disposal. This chapter focuses on the structural integrity issues concerning strength, stability, fatigue life and damage tolerance of hybrid composite-aluminium aircraft structures.

Military aircraft certification is governed by specifications such as the US MILSTD-1530 [1] and the UK Defence Standard [17], which aim to ensure the structural integrity of an aircraft system through implementation of regulations and requirements into a procedure consisting of a series of analytical and test related tasks, see Fig. 3.

Based on the mission analysis, a user profile is established and applied as input to the load analysis, which determines the magnitude and distribution of significant static and dynamic loads, that the aircraft structure may encounter during the

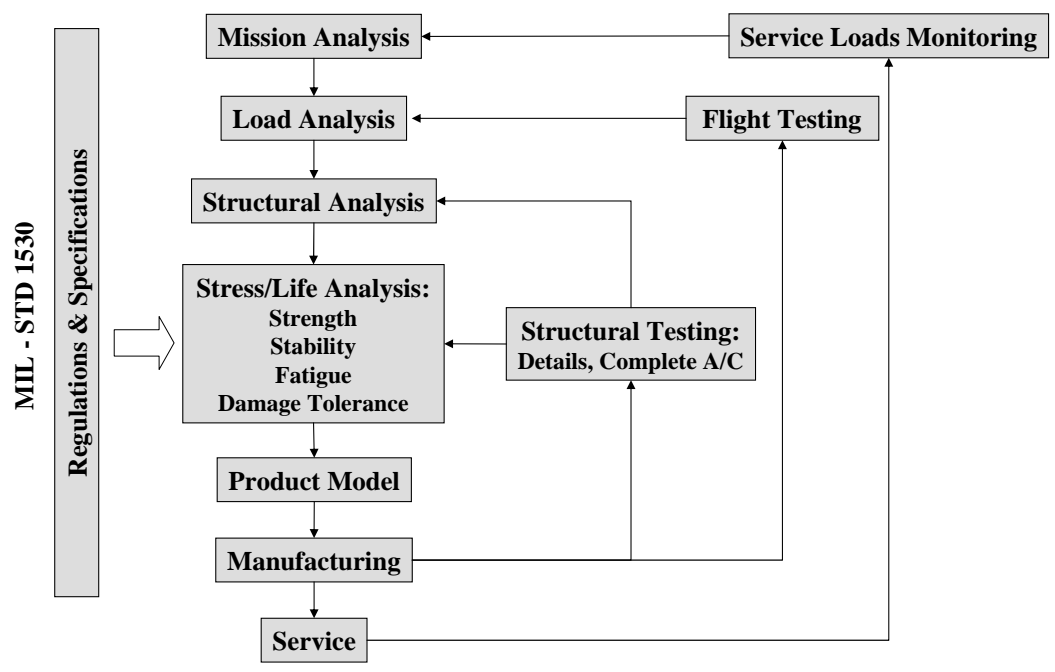

Figure 3. Aircraft structural integrity procedure. 
service. Based on these loads, the structural FE-analysis of the whole aircraft is performed in order to determine the load distribution.

The stress and life analyses are central tasks in the dimensioning of structural components. The analyses include determination of the stresses, strains and deformations which result from the external loads and environment imposed on the aircraft structure. In the static strength and stability assessments, the structure is required to be able to carry the limit load, without acquiring detrimental deformations which would interfere with its safe operational and maintenance capabilities, and the ultimate load without rupture or collapsing failure. The limit load is a load level which is expected not to be exceeded during the aircraft operational life and the ultimate load is the limit load times a statistical safety factor. The fatigue and damage tolerance assessments are conducted, on the basis of the design load spectra, to substantiate the ability of the structural components to sustain the initiation and growth of defects during cyclic loading, until they can be detected. Another important task in the structural integrity assessment process is the structural testing. Testing can sometimes be performed in early design stages to estimate the potential of a certain concept, but is required for verification of the final full-scale design assembly, in order to demonstrate its static strength, fatigue life and damage tolerance capability.

The framework outlined above is generally applicable for all materials but is implemented using different approaches and methods for composites and for aluminium, because of their dissimilar material characteristics. For instance, plastic behaviour of aluminium is taken into account when its response is evaluated in relation to the limit and ultimate load, and buckling of thin aluminium structures is allowed as long as the strength and deformation criteria are fulfilled. In the damage tolerance approach for aluminium, an initial crack is assumed to exist at the most stressed spot, and is allowed to grow stably to a certain non-critical length under operational loads. Analytical methods for fatigue and crack growth in aluminium, including crack initiation, crack growth and residual strength are well-established. In test verification of aluminium parts, the highest spectrum loads are disregarded because they may introduce beneficial compressive residual stresses which delay crack initiation and growth. To cover the variability in the aluminium fatigue material properties in testing, safety factors are used on design service life. For composites, the high spectrum loads are included in the verification testing because they inflict damage in the composite. The variability of composite fatigue properties is believed to be significantly larger than that of aluminium, which is why higher safety factors on design service life are required [18], and consequently longer testing time. An alternative approach is to use an enhancement factor on the load level instead. The problem arises in verification testing of hybrid structures because of the incompatibility of the methods used for each of the constituents.

Unlike metals, composite materials are assumed to have linear elastic response until failure. Buckling of composite panels is generally not allowed at any load level because of the sensitivity of composites to out-of-plane stresses and delami- 
nation. Damage tolerance for composites is imposed by considering defects, such as delaminations and barely visible impact damages, which are not allowed to grow at all under operational loads or high static loads. Fatigue and damage tolerance analysis, similar to the one used for metals, is generally not implemented for composites. Instead, the fatigue and damage tolerance is addressed by design precautions, i.e. avoiding out-of-plane stresses, and making sure that the applied strain is below a proven limit, e.g. the allowable compressive strain for a plate with an open hole. This approach results in relatively low allowed strains in the composite and usually a conservative design. The analytical techniques used for assessment of composite structures are heavily related to testing and are preferably developed within the Building Block Approach [19, 20]. Initially, a large number of small specimens are tested and the analytical methods are adapted for this structural level. Then, increasingly complex structural components are tested and the analytical methods are adjusted accordingly, based also on the knowledge acquired in the previous step. By this approach, the risks in technology associated with the complexity of composites may be detected and eliminated at an early stage.

However, such approach might be inappropriate for assessment of hybrid structures, since the hybrid effects, e.g. thermally induced loads, are absent at the small-specimen level. Also, the large diversity of possible failure modes and different material property variability of the constituent materials makes it difficult to determine beforehand the critical mode for a large hybrid structure. For these reasons, large hybrid structures should be tested in the beginning of the assessment, in order to include the hybrid effects and to determine the critical failure modes at an early stage. Such testing can be very complex and hard to evaluate, and a lot of understanding can be acquired by numerical simulations of the structural behaviour prior to the testing.

In Paper I, a numerical conceptual study of the wing box in Fig. 2 was performed, involving two different hybrid designs, which were dimensioned against the limit load, ultimate load and design load spectrum, according to the strength, stability, fatigue and damage tolerance requirements described above. The structural behaviour of the two wing box concepts, in terms of the failure modes, the interaction between composite and aluminium, the thermally induced loads and the mass was studied. An alternative set of requirements for the composite was then considered, with the aim to challenge the conservatism of the current design rules and to study the effect of alternative requirements on the structural behaviour and their impact on the mass. In the alternative requirement set, buckling was permitted above a certain load level and the allowable strain was determined from residual strength tests of impacted specimens.

In the conceptual study, simplified methods were used to assess and compare the structural behaviour of the two concepts. More accurate predictions of structural behaviour require reliable modelling techniques for composite failure, for which thorough understanding of the physical aspect of the failure process is needed. This is the topic of the next chapter. 



\section{Failure of CFRP composites}

Typical CFRP composite laminates are manufactured from several unidirectional layers (also referred to as plies or laminae) of carbon fibre reinforced polymer resin, stacked in different directions on top of each other, see Fig. 4, and bonded by curing under elevated pressure and temperature.

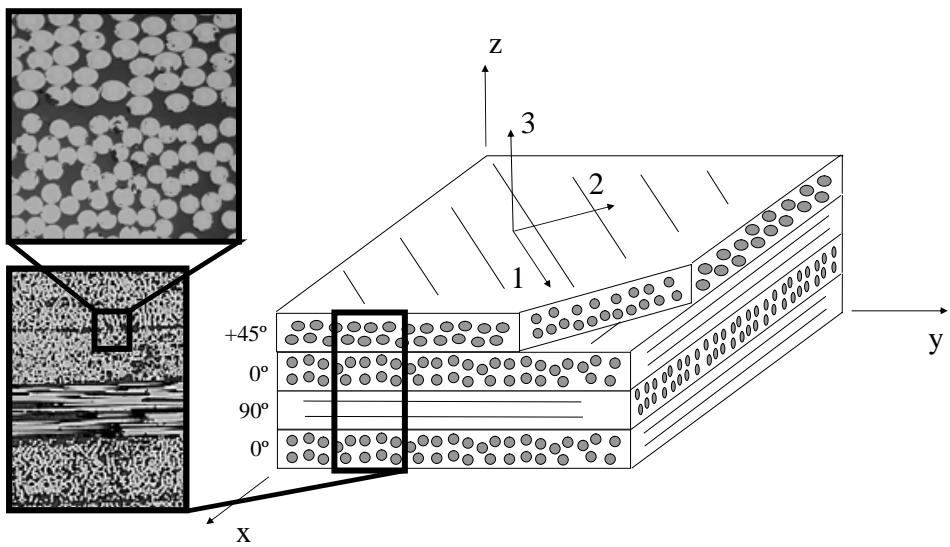

Figure 4. Composite laminate with local and global coordinate systems.

Each ply in itself is a non-homogeneous composition and is usually considered to be orthotropic. The ply strength and stiffness are high in the longitudinal (1-dir, parallel to the fibres) direction and low in the transverse (2-dir, perpendicular to the fibres) and the out-of-plane (3-dir) directions, as shown in Table 1. This property can be exploited to customize the stiffness and the strength of the laminate in different directions, by tailoring the layup sequence to suit the particular application. Normally, the laminates are designed to be fibre controlled, i.e. most of the loads are transferred through the fibres. An example of a fibre controlled laminate layup is the quasi-isotropic layup, which is a symmetric layup with an equal number of plies oriented in $0^{\circ}, \pm 45^{\circ}$ and $90^{\circ}$ directions with respect to the global x-axis. Table 1 shows the properties of a quasi-isotropic layup laminate and of AA7010, an aluminium alloy extensively used in aircraft industry. In comparison to AA7010, the composite has a higher strength-to-weight ratio and almost a negligible thermal expansion coefficient. 
Unidirectional CFRP composites, where all plies are oriented in the same direction, typically exhibit a stress-strain relation in the longitudinal and transverse loading directions which is nearly linear until the onset of failure [10-12], whereupon the material softens. The in-plane shear stress-strain relation is non-linear due to the plastic deformation of the matrix $[10,13,21]$. However, in multi-directional composites, the effect of the shear non-linearity is small, due to the fibre controlled design of the laminate.

Table 1. Typical elastic, strength and thermal expansion properties of HTA/6376 CFRP unidirectional composite (UD) [19], quasi-isotropic layup (QI) and aluminium alloy AA7010 [22] at room temperature.

\begin{tabular}{llccc}
\hline Property & & $\begin{array}{c}\text { HTA } 6376 \\
\text { (UD) }\end{array}$ & $\begin{array}{c}\text { HTA } / 6376 \\
(\mathrm{QI})\end{array}$ & AA7010 \\
\hline Longitudinal modulus & $E_{11}(\mathrm{GPa})$ & 137 & 54 & 70 \\
Transverse modulus & $E_{22}(\mathrm{GPa})$ & 10 & 54 & \\
Out-of-plane modulus & $E_{33}(\mathrm{GPa})$ & 11 & 11 & \\
In-plane shear modulus & $G_{12}(\mathrm{GPa})$ & 5.2 & 21 & 26 \\
Out-of-plane shear modulus & $G_{13}(\mathrm{GPa})$ & 5.2 & 4.5 & \\
Out-of-plane shear modulus & $G_{23}(\mathrm{GPa})$ & 3.9 & 4.5 & \\
In-plane Poisson's ratio & $\nu_{12}$ & 0.3 & 0.3 & \multirow{2}{*}{0.33} \\
Out-of-plane Poisson's ratio & $\nu_{13}$ & 0.5 & 0.33 & \\
Out-of-plane Poisson's ratio & $\nu_{23}(\mathrm{MPa})$ & 2250 & 80.33 & \multirow{2}{*}{490} \\
Longitudinal tensile strength & $X_{T}(\mathrm{MPa})$ & 1600 & & \\
Longitudinal compressive strength & $X_{C}(\mathrm{MPa})$ & 65 & & \\
Transverse tensile strength & $Y_{T}(\mathrm{MPa})$ & 300 & & \\
Transverse compressive strength & $Y_{C}(\mathrm{MPa})$ & 30 & & \\
Out-of-plane tensile strength & $Z_{T}(\mathrm{MPa})$ & 344 & & \\
Out-of-plane compressive strength & $Z_{C}(\mathrm{MPa})$ & 120 & & \\
In-plane shear strength & $S_{12}(\mathrm{MPa})$ & 80 & & \\
Out-of-plane shear strength & $S_{13}(\mathrm{MPa})$ & 80 & & \\
Out-of-plane shear strength & $S_{23}(\mathrm{MPa})$ & -0.2 & 2.1 & 23.4 \\
Longitudinal thermal expansion coeff. & $\alpha_{11}\left(10^{-6{ }^{\circ}} \mathrm{C}^{-1}\right)$ & -1 & \\
Transverse thermal expansion coeff. & $\alpha_{22}\left(10^{-6{ }^{\circ}} \mathrm{C}^{-1}\right)$ & 28.0 & 2.1 & \multirow{2}{*}{2820} \\
Density & $\rho\left(\mathrm{kg} / \mathrm{m}^{3}\right)$ & 1640 & 1640 & 2820 \\
\hline
\end{tabular}

\subsection{Static failure}

Failure of composite laminates is a complex process driven by several damage mechanisms and influenced by the heterogeneous characteristics of the material. Thus, accounting for all different damage types and their interaction is a very complicated matter. However, in order to derive useful failure prediction models, the complex damage modes are often simplified and classified into two main categories [9]: intralaminar and interlaminar damage modes. The intralaminar damage modes take place within a ply and are mainly triggered by in-plane loads, while the interlaminar damage occurs between the laminae and is a result of out-of-plane stresses. 


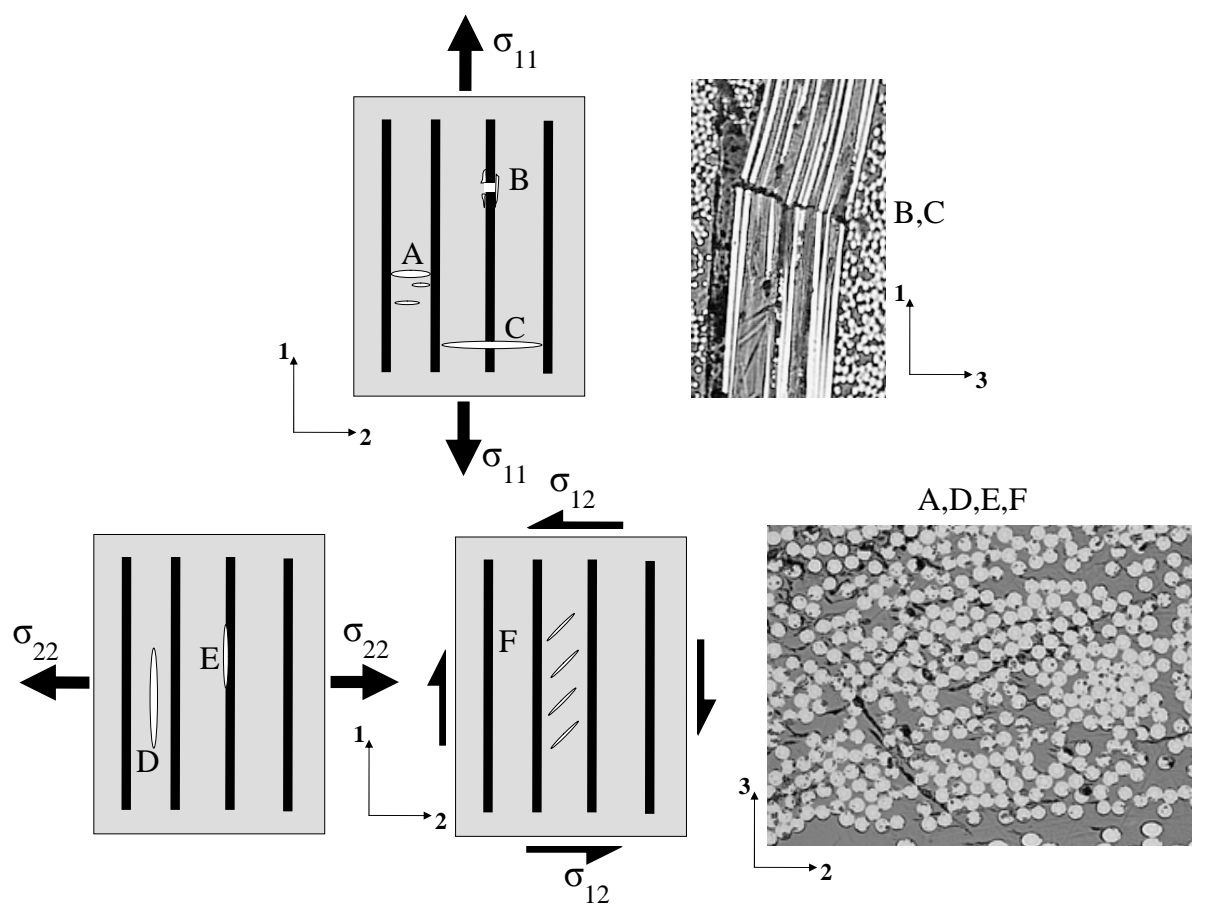

Figure 5. Intralaminar damage modes in longitudinal (1-dir) tensile, transverse (2-dir) tensile and in-plane shear loading. A) Matrix cracking. B) Fiber fracture with weak fiber/matrix interface. C) Fiber fracture with strong fiber/matrix interface and brittle matrix. D) Matrix cracking. E) Fiber/matrix interfacial debonding. F) Matrix cracking.

A further distinction is made between tensile and compressive damage, and fibre and matrix dominated intralaminar failure, see Figs. 5 and 6 . The tensile load in the lamina longitudinal direction is mainly carried by the fibres and, naturally, the strength depends on the fracture properties of the fibres. Similarly, the tensile transverse and shear loading result in matrix cracking and the strength is mainly depending on the properties of the matrix.

Compressive loading results in different types of failure than in the tensile cases. In the lamina longitudinal direction, fibre-buckling or kinking mechanisms are usually triggered, preferably where initial misalignments of the fibres are present [23]. Although this failure is sometimes refereed to as being fibre dominated, the initiation and the progression of the damage depends on the properties of both the fibres and the matrix. Failure in compressive transverse loading takes place on an inclined plane in the matrix and through the fibre-matrix interfaces. The cracking is driven by the resolved shear stress acting on the plane of fracture [10, 24].

The classification of the failure modes, briefly described above, is an idealized framework which, by no means, gives the complete description of the failure in a 

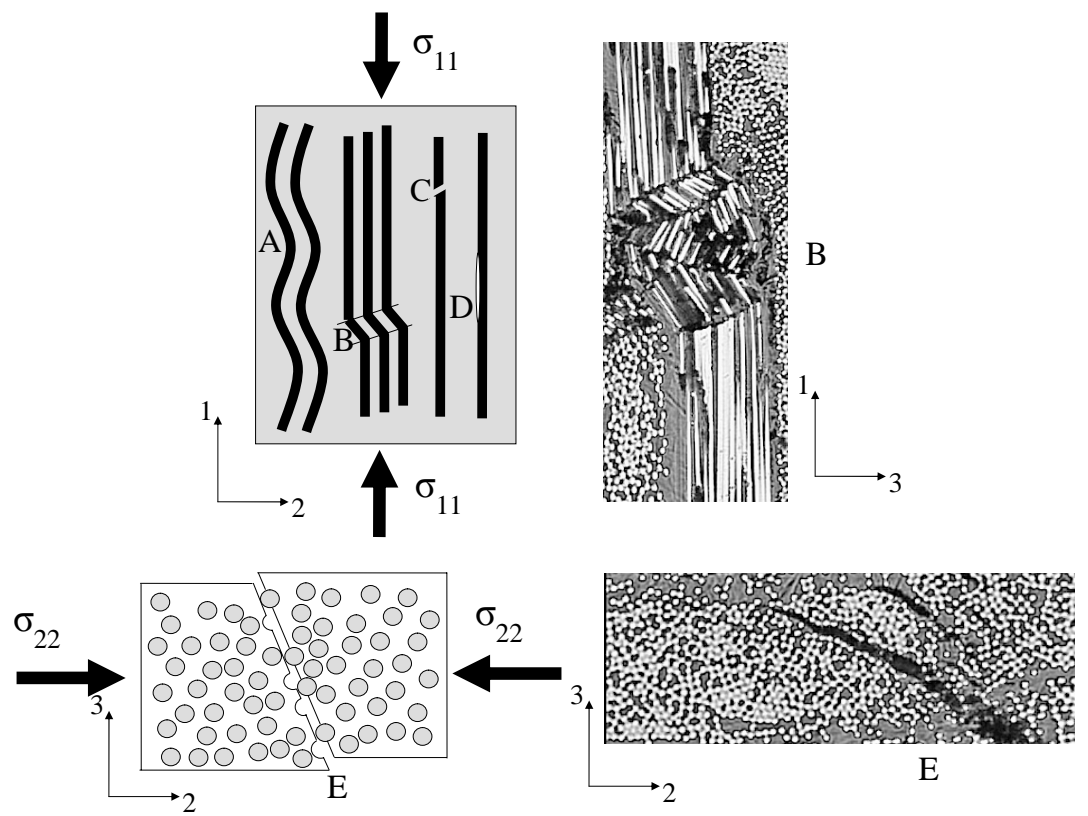

Figure 6. Intralaminar damage modes in longitudinal (1-dir) and transverse (2-dir) compressive loading. A) Elastic micro-buckling. B) Plastic micro-buckling and kinkband formation. C) Fiber shear fracture. D) Fiber/matrix interfacial debonding. E) Matrix shear fracture under compressive load.

composite ply. For instance, it disregards the interaction of the failure modes with each other in a general loading situation. Nevertheless, recognition of the diversity of the damage mechanisms in the composite is a valuable insight which indeed improves development of failure prediction models.

The failure behaviour of multidirectional laminates is even more complex. Each ply in the laminate is exposed to a different local stress state and the actual failure mode will therefore vary through the stack. Once the most critical ply in the stack has began to fail, the stresses will redistribute to the remaining plies, which then might fail themselves. Thus, the failure of the laminate occurs progressively until no further loading can be supported. The presence of multiple plies within a laminate can also have an effect on the the failure progression in the neighbouring layers, i.e. crack growth in a ply might be restricted by the neighbouring plies, which gives an increase of the apparent strength of the cracked ply, an effect known as the in-situ effect [25].

The interlaminar failure in multidirectional laminates takes place in the resin rich interface area, in the plane between the neighbouring plies. The crack growth is driven by the out-of-plane stresses and results in separation of the laminae, which is why it is often referred to as delamination. Due to the low strength of the 
resin, CFRP laminates generally have a poor interlaminar strength. Delaminations can easily form from imperfections in the interface, intralaminar matrix cracks or relatively light impact loading. A typical delamination pattern, caused by a lowvelocity impact, through the section of the wing skin of Gripen is shown in Fig. 7. Such type of damage significantly reduces the in-plane compressive strength of the laminate and is difficult to detect. The sensitivity of CFRP laminates to interlaminar failure is a major drawback because it diminishes the advantage of high strength of the fibres and instead lets the matrix properties govern the structural strength.

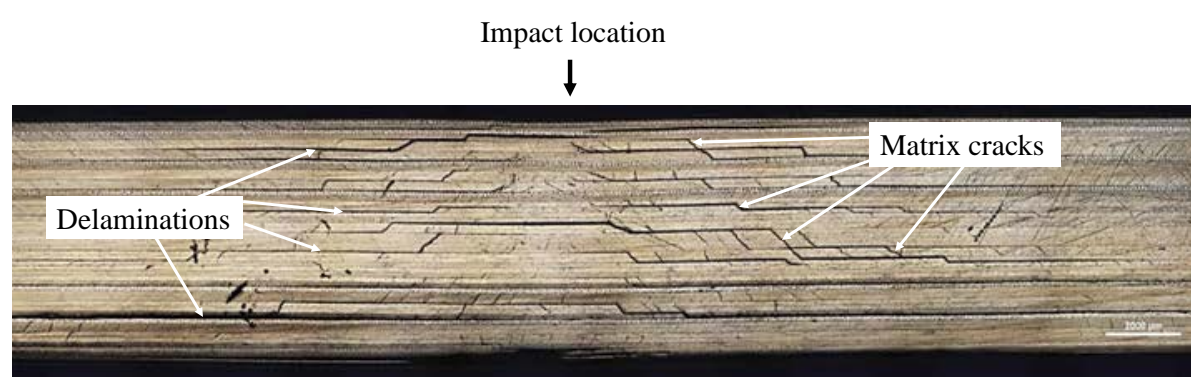

Figure 7. Low-velocity impact damage in the wing skin of the Gripen aircraft.

\subsection{Fatigue failure}

Fatigue of metals has been studied for a significantly longer time than fatigue of composites, and today the phenomenon is reasonably well-understood, [26, 27]. Unfortunately, the fatigue of composites has in many contexts been treated using the framework that was developed for metal fatigue, which in most cases is not quite relevant. Metal fatigue mechanisms, i.e. dislocation movement, initiation of microcracks and growth of a single dominant crack to unstable failure, do not apply to composite fatigue. In composites, the fatigue process is driven by the same damage mechanisms as in quasi-static loading [9], see Figs. 5 and 6, i.e. matrix cracking, fibre fracture/kinking, fibre-matrix debonding and interlaminar cracking.

In unidirectional laminates, the predominant damage mechanism depends on the loading direction (on-axis, off-axis, tensile or compressive), strain level and material properties. Tensile fatigue loading in longitudinal direction results in fibre breakage at high strain levels (type $\mathrm{B}$ and $\mathrm{C}$ in Fig. 5), matrix cracking which may trigger fibre-matrix interfacial cracking at intermediate strains (type A and E) and matrix cracking at low strains (type A) [9]. The fatigue limit is governed by the fatigue limit of the matrix. Compressive fatigue may involve micro-buckling of the fibres. If the load is inclined to the fibre direction the cracks will initiate either in the matrix (type D or F) or in the fibre-matrix interface (type E) and propagate along the fibres. 
Generally, the fatigue failure in multidirectional laminates is initiated by matrix cracking or/and fibre-matrix interface debonding. The cracking occurs at increasing number of locations in the composite and may propagate during the cycling. As the loading continues, the intralaminar cracks propagate, which in turn increases the interlaminar stresses and promotes delamination and further matrix cracking [28]. The fatigue damage increase is also accompanied by reduction of the stiffness and of the in-plane stress concentrations. Eventually, the matrix will degrade to the point where it no longer can support the fibres and micro-buckling (at compressive loading) and fibre fracture (at tensile loading) will take place. At this stage, the structural failure is imminent. The contribution of each mechanism to the total fatigue damage varies depending on the loading state, frequency, stacking sequence, geometry, material properties, environment etc.

\subsection{Bolted joints}

The failure of composite material in shear loaded bolted joints is, on micro level, driven by the damage mechanisms described in the previous two sections. On structural (or macroscopic) level, several different failure modes can be distinguished [29], and the most common ones are shown in Fig. 8.
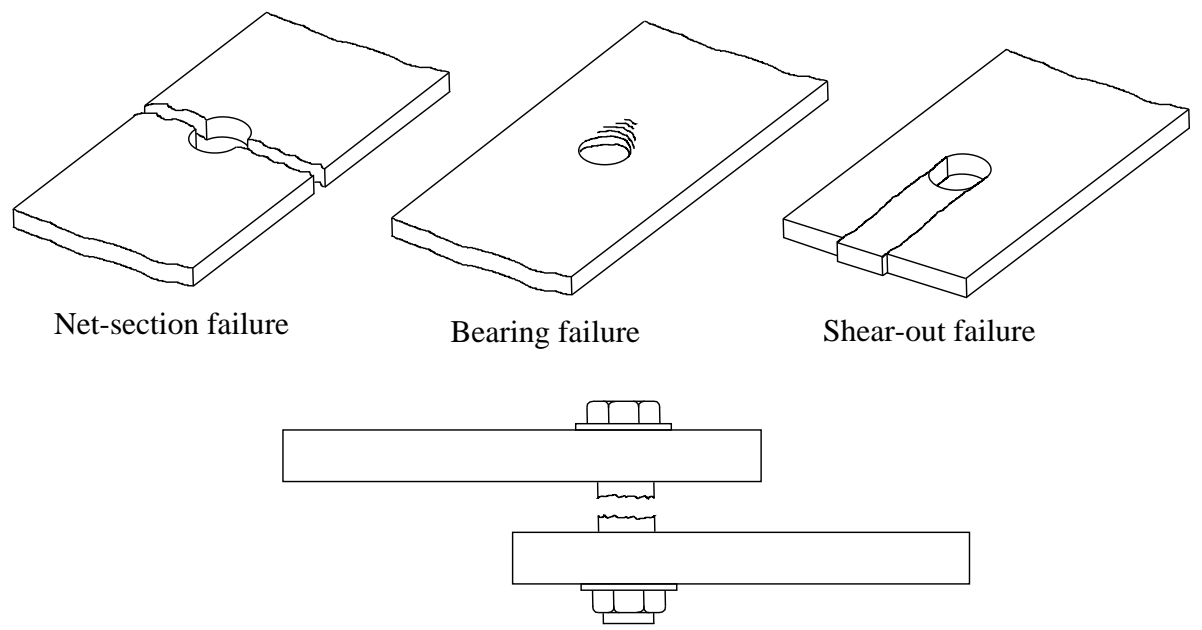

Bolt failure

Figure 8. Structural failure modes of composite in a bolted joint.

Net-section failure occurs due to the by-pass loads which cause tangential stresses at the hole edge. It is much like the failure in an open hole plate and occurs for high hole diameter to plate width ratios. Bearing failure is a compressive failure mode which is caused by the contact pressure acting on the hole edge. In contrast 
to the other failure modes, the damage in bearing failure is developed gradually, which increases the probability of detection and makes this the preferred failure mode. Shear-out mode occurs due to shear stresses where the edge distance is short. The failure of the bolt is caused by the shear and the bending stresses in the bolt shank and occurs often as a secondary failure mode after the bearing failure has already been initiated. The focus of this work is on the bearing failure.

As seen in multiple experimental studies [30-35], the static bearing failure process begins with intralaminar matrix cracking at the hole edge, followed by fibre cracking and delamination. Finally, fibre kinking takes place at the hole edge and spreads thereafter in the radial direction, whereupon structural failure occurs. Similarly, studies of bearing failure in cyclic loading [36-42], reveal matrix shear cracking and delamination and in some cases bolt fatigue failure. Significant increase in compliance, accompanied by hole elongation is observed during the cycling. Bearing failure is specific in the sense that most of the damage accumulation takes place in the area of contact between the bolt and the bolt hole edge. The material softening that takes place affects the contact area and how the force is transmitted from the bolt to the hole edge during the loading. This has influence on the strength and the stiffness of joint and it also creates convergence difficulties in the context of numerical simulation.

There are many other factors that influence the failure behaviour and the strength of shear loaded bolted joints [43] and many of them have been studied in the literature using both experimental and analytical methods. Some examples are laminate type, friction [44], secondary bending and bolt tilting [45, 46], amount of by-pass and bearing load [47], fastener type (countersunk or protruding head) [31-33, 36, 48, 49], load transfer [50], pretension, [51], clearance [52-54] etc. Most of the studies were performed on specimens with only a few bolts and in some cases only one.

In order to produce accurate numerical predictions of the joint failure, the joint model needs to be able to take into account these factors. This usually results in a detailed, computationally heavy model and long analysis time, which means that only a few bolts can be included in the analysis. For the problems including many fasteners, e.g. the thermally induced loads in a long joint, some simplifications must be introduced in order to have a manageable model. In Paper II, a method was developed to incorporate the local failure behaviour of a single-bolt, compositealuminium joint into a large FE-model using simple line elements. The method was demonstrated on the box structure in Fig. 2, where the progressive failure of the bolts was studied in bending/twisting loading of the box at elevated temperature. Modelling details are described in Chapter 6.

The effect of the thermally induced loads on the local behaviour of a joint is difficult and expensive to study experimentally in a long joint. In order for the thermally induced bolt loads to arise, the structure would have to be exposed to elevated temperature, which is a difficult task to perform in an experimental setup. Furthermore, to study the failure, it is desirable to test several objects to 
increase the statistical confidence of the results and also to explore different testing conditions.

Typically, the thermally induced bolt loads in a rib-wise airframe joint are directed normal to the mechanical loads and distributed so that the maximal bolt load is obtained at the end-bolt in the joint, see Fig. 9(a), creating a biaxial bearing load state. In Paper III, Paper IV and Paper V, a simple two-bolt CFRP composite test specimen is used, see Fig. 9(b), that simulates the biaxial loading situation at the end-bolt in a long joint. The thermally induced bolt loads are applied by mechanical actuators. The small size of the specimen facilitates its manageability and allows for easy application of the elevated ambient temperature conditions. Further details of the conducted experiments are presented in Chapter 4.

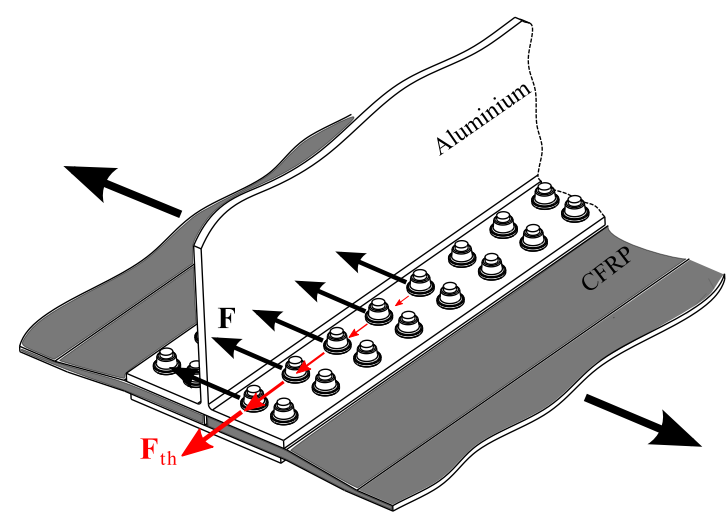

(a) Hybrid joint.

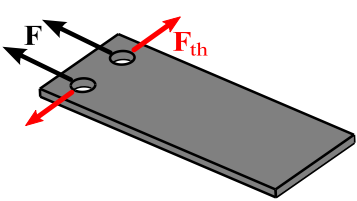

(b) Two-bolt specimen.

Figure 9. Mechanically and thermally induced bolt loads in a composite plate in a hybrid bolted joint, and a simple two-bolt specimen.

The described failure of composite in static and cyclic loading, and in the bolted joints is used as the basis for the modelling work, which is described in Chapters 5 and 6. 


\section{Experimental work}

The purpose of this experimental study was to investigate the effects of biaxial bearing loading on the failure behaviour of CFRP composite in static, constant amplitude and spectrum loading, and also to study the damage mechanisms in order to understand the failure process. The biaxial loading is applied in a specifically designed test rig and the damage observations are performed using an optical microscope.

\subsection{Test setup}

The experiments were conducted on two-bolt specimens, see Fig. 9(b), in a doublelap joint arrangement. A rig was designed where the mechanical load, $F$ and the thermally induced load, $F_{t h}$, were applied to the specimens via four L-shaped steel plates, which were bolted to the specimens, see Fig. 10.

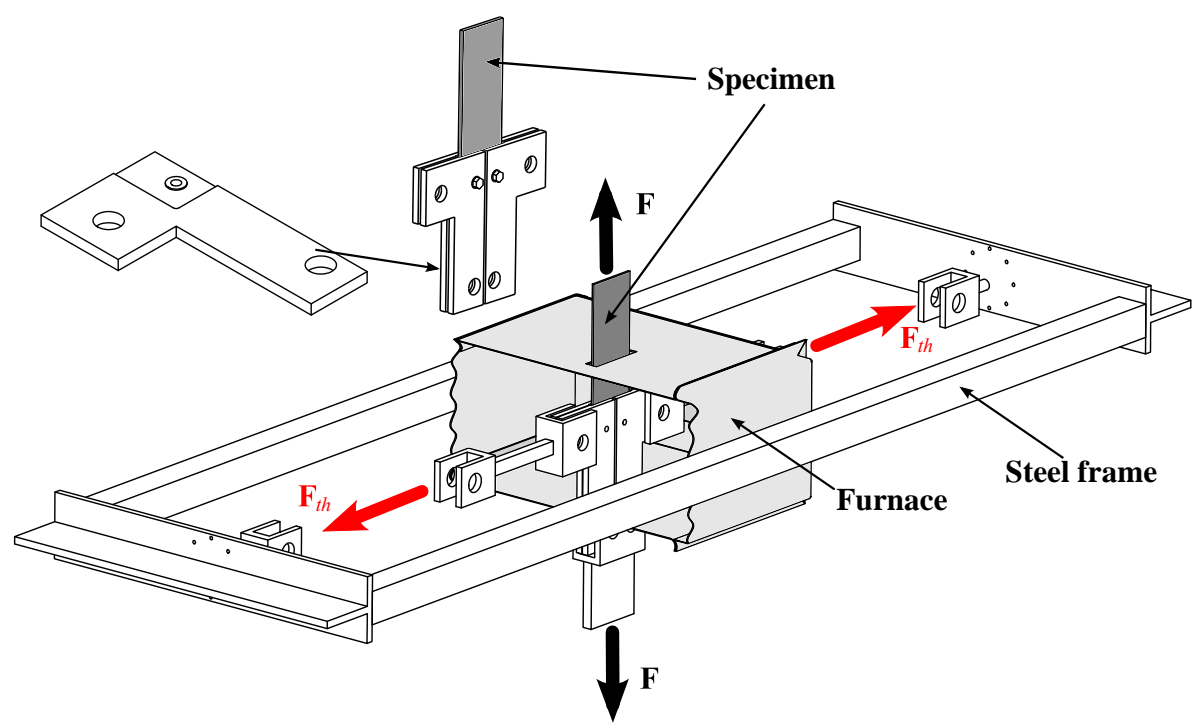

Figure 10. Experimental setup. 
The mechanical load was imposed in the vertical direction, by the vertical load frame, while the thermally induced load was applied, independently of the mechanical load, in the horizontal direction by actuators connected to a surrounding steel frame. By this arrangement, a biaxial bearing load state was applied to the specimens in static, constant amplitude and spectrum loading. To achieve elevated temperature, the specimens were placed inside a metal furnace where the air was heated to $90^{\circ} \mathrm{C}$.

Five specimens were tested in static loading, 16 in constant amplitude loading and 18 in spectrum loading. For the spectrum loading, a standard fighter aircraft wing bending spectrum FALSTAFF [55] was used. All biaxially loaded specimens were exposed to a constant thermally induced load at a level of approximately half of the static bearing strength, which was applied prior to the mechanical load. The applied load, the grip displacements in the vertical and horizontal directions and the number of cycles to failure were recorded. Most of the specimens were loaded to failure while three tests were interrupted prior to failure, whereupon the specimens were cut along the bearing plane and examined in an optical microscope.

\subsection{Damage observations}

Figures 11 and 12 show the images of the bearing planes of the three specimens that were examined.

In the quasi-statically loaded specimen, Fig. 11, the damage manifests itself as distinct inclined shear bands consisting of kinked plies and matrix cracks, which seem to initiate at the hole edge and then spread inwards the laminate. Delaminations

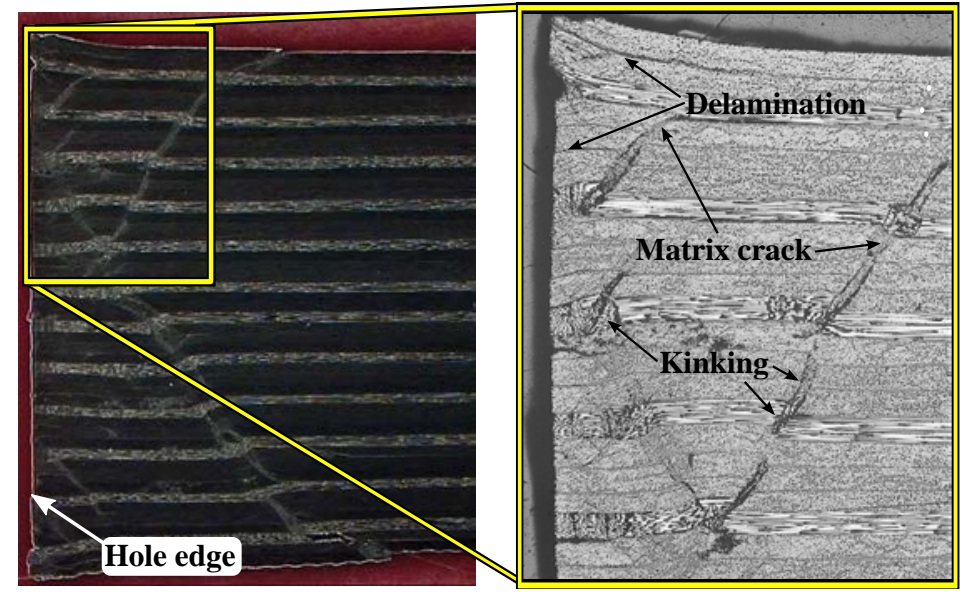

Figure 11. Microscope images of the bearing plane of the uniaxially statically loaded specimen at $90 \%$ of the failure load. 
were also observed near the bolt hole. A detailed discussion of the static testing results is included in Paper III.

In the specimens loaded uniaxially and biaxially at constant amplitude, Fig. 12, the damage pattern appears to be different than in the static loading case. No distinct shear bands are observable, instead extensive crushing of the hole edge is seen, where ply fracture, matrix cracking and delamination have taken place. Further away from the hole, the plies seem to have bent continuously, without being kinked. Zooming in into this area reveals extensive matrix micro-cracking and fibre-matrix debonding damage. A more detailed discussion is presented in Paper IV, where these damage modes were identified as the driving mechanisms of the fatigue failure.
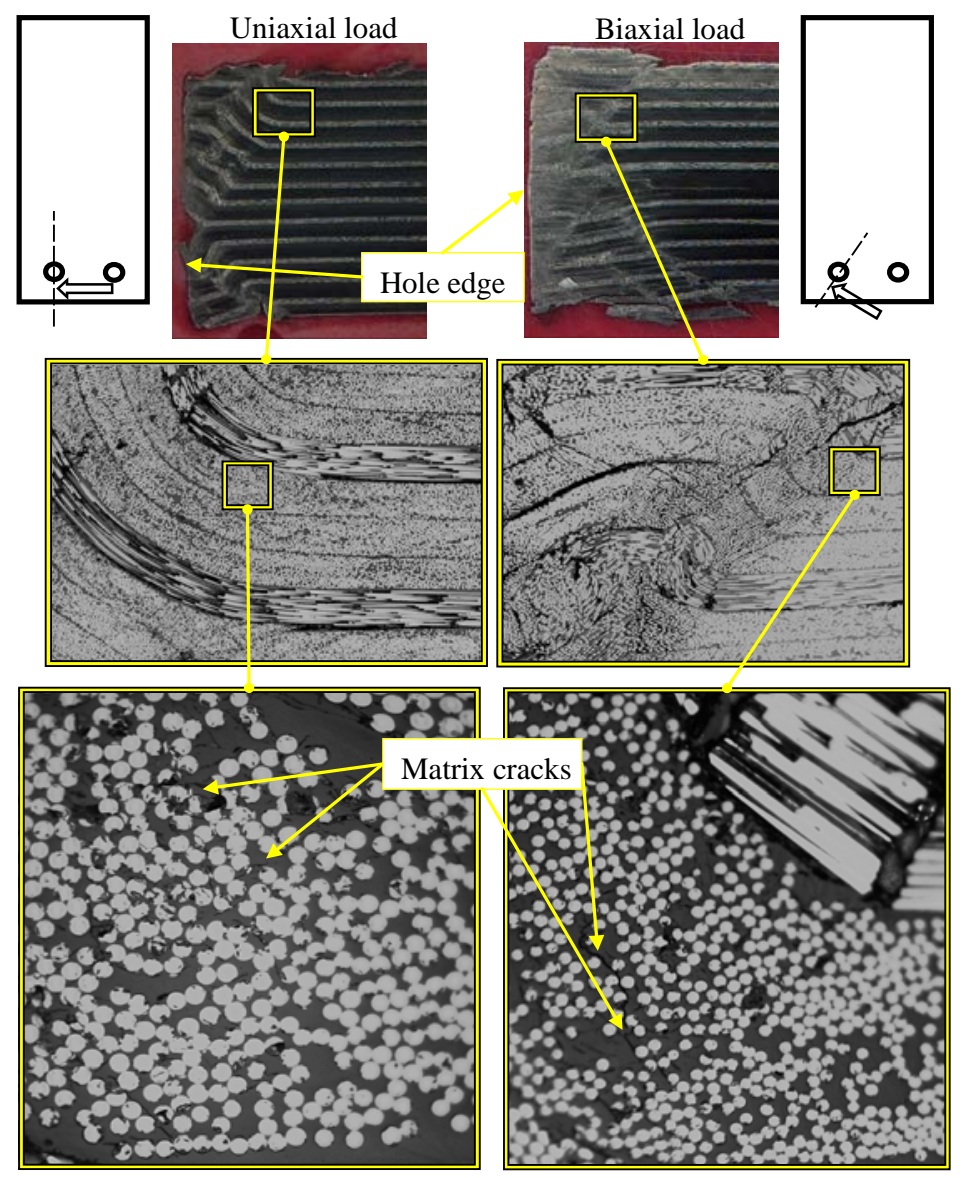

Figure 12. Microscope images of the bearing plane of the uniaxially and biaxially loaded specimens at constant amplitude, after half of the fatigue life. 
Another observation, which was made both in constant amplitude loading in Paper IV and in spectrum loading in Paper V, was that the joint compliance increased continuously during the cycling. The increase was noticed in both uniaxial and biaxial loading and was attributed to the softening of the composite material in the area around the hole due to the fatigue damage accumulation.

In static loading, the resultant bolt load at failure was nearly the same in uniaxial and biaxial loading, i.e. the thermally induced load had no effect on the static bearing strength. In constant amplitude and spectrum loading, however, longer fatigue life was obtained in biaxial loading for the same maximum resultant bolt load, although a large scatter was observed in the fatigue life of the spectrum loaded specimens. This effect was explained by the lower stress range in the biaxial case. These results can be utilized in dimensioning situations to conservatively design biaxially loaded bolt holes based on data obtained in uniaxial loading. 


\section{Material modelling}

This chapter presents material modelling techniques for composite laminates. More specifically elastic behaviour, quasi-static failure including failure initiation and damage progression, and fatigue life prediction will be discussed. Some of the models are utilized in this research work in a modified form while others are presented for the sake of completeness.

\subsection{Elastic behaviour}

A thorough description of elastic behaviour of composite plates can be found in $[11,12,56]$. On the micro level, each lamina of FRP material is a heterogeneous unit consisting of fibres and matrix, see Fig. 4. The macro mechanical view of a lamina involves combining the properties of the constituents into homogeneous lamina properties. The elastic constitutive response of any material point within a lamina is then described by Hooke's generalized law

$$
\sigma_{i j}=C_{i j k l} \varepsilon_{k l} \quad \text { or } \quad \varepsilon_{i j}=S_{i j k l} \sigma_{k l}
$$

where $C_{i j k l}$ and $S_{i j k l}$ are the fourth-order homogenized stiffness and compliance tensors respectively, and where $\sigma_{i j}$ and $\varepsilon_{k l}$ are the stress and strain tensors, respectively. Both the stiffness and the compliance tensor have minor and major symmetry properties and are positive definite. If the lamina is considered to be orthotropic and the material coordinate axes are chosen as the local lamina material directions 1, 2, 3 in Fig. 4, the second relation in Eq. (5.1) can be written in matrix form using Voigt notation in terms of engineering elastic constants as 


$$
\left[\begin{array}{c}
\varepsilon_{11} \\
\varepsilon_{22} \\
\varepsilon_{33} \\
2 \varepsilon_{12} \\
2 \varepsilon_{13} \\
2 \varepsilon_{23}
\end{array}\right]=\left[\begin{array}{cccccc}
\frac{1}{E_{1}} & \frac{-\nu_{21}}{E_{2}} & \frac{-\nu_{31}}{E_{3}} & 0 & 0 & 0 \\
\frac{-\nu_{12}}{E_{1}} & \frac{1}{E_{2}} & \frac{-\nu_{32}}{E_{3}} & 0 & 0 & 0 \\
\frac{-\nu_{13}}{E_{1}} & \frac{-\nu_{23}}{E_{2}} & \frac{1}{E_{3}} & 0 & 0 & 0 \\
0 & 0 & 0 & \frac{1}{G_{12}} & 0 & 0 \\
0 & 0 & 0 & 0 & \frac{1}{G_{13}} & 0 \\
0 & 0 & 0 & 0 & 0 & \frac{1}{G_{23}}
\end{array}\right]\left[\begin{array}{c}
\sigma_{11} \\
\sigma_{22} \\
\sigma_{33} \\
\sigma_{12} \\
\sigma_{13} \\
\sigma_{23}
\end{array}\right]
$$

where $E_{1}, E_{2}, E_{3}$ are Young's moduli in the principal material directions, $\nu_{i j}, i \neq j$ are Poisson's ratios and $G_{12}, G_{13}, G_{23}$ are shear moduli. The symmetry of the compliance matrix implies the relation

$$
\frac{\nu_{i j}}{E_{i}}=\frac{\nu_{j i}}{E_{j}}
$$

with no sum on $i$ and $j$, which results in 9 independent coefficients. If the thickness of a lamina is considered to be small compared to its other dimensions, as in the membrane or shell finite element formulations, the state of plane stress is assumed, which cancels the third, the fifth and the sixth row and column of the compliance matrix in Eq. (5.2). Inverting the plane stress relation, the following equations are obtained

$$
\left[\begin{array}{l}
\sigma_{11} \\
\sigma_{22} \\
\sigma_{12}
\end{array}\right]=\frac{1}{1-\nu_{12} \nu_{21}}\left[\begin{array}{ccc}
E_{1} & \nu_{21} E_{1} & 0 \\
\nu_{12} E_{2} & E_{2} & 0 \\
0 & 0 & \left(1-\nu_{12} \nu_{21}\right) G_{12}
\end{array}\right]\left[\begin{array}{c}
\varepsilon_{11} \\
\varepsilon_{22} \\
2 \varepsilon_{12}
\end{array}\right] \quad \text { or } \quad \boldsymbol{\sigma}=\boldsymbol{Q} \boldsymbol{\varepsilon}
$$

where $\boldsymbol{\sigma}$ is the stress matrix, $\boldsymbol{\varepsilon}$ is the strain matrix and $\boldsymbol{Q}$ is the lamina stiffness matrix.

The equations presented above are used within the classical laminate plate theory [56] to construct the corresponding relation for a laminate. Assuming uniform laminae thickness and applying the Kirchhoff assumption, i.e. that the straight lines perpendicular to the mid-surface of the plate remain straight, perpendicular and inextended after the deformation, the laminate strain matrix can be written as 


$$
\bar{\varepsilon}=\bar{\varepsilon}_{0}+z \bar{\kappa}
$$

where $\bar{\varepsilon}=\left[\begin{array}{lll}\varepsilon_{x} & \varepsilon_{y} & \gamma_{x y}\end{array}\right]^{T}$ is the laminate strain matrix given in the global coordinate system, $\bar{\varepsilon}_{0}=\left[\begin{array}{lll}\varepsilon_{x 0} & \varepsilon_{y 0} & \gamma_{x y 0}\end{array}\right]^{T}$ is laminate mid-surface strain matrix, $\overline{\boldsymbol{\kappa}}=\left[\begin{array}{lll}\kappa_{x} & \kappa_{y} & \kappa_{x y}\end{array}\right]^{T}$ is the laminate curvature matrix and $z$ is the distance from the laminate mid-plane in the thickness direction.

Cross sectional distributed force and moment matrices $\boldsymbol{N}=\left[\begin{array}{lll}N_{x} & N_{y} & N_{x y}\end{array}\right]^{T}$ and $\boldsymbol{M}=\left[\begin{array}{lll}M_{x} & M_{y} & M_{x y}\end{array}\right]^{T}$ are defined according to

$$
\left[\begin{array}{l}
N \\
M
\end{array}\right]=\left[\begin{array}{ll}
A & B \\
B & D
\end{array}\right]\left[\begin{array}{c}
\bar{\varepsilon}_{0} \\
\bar{\kappa}
\end{array}\right]
$$

where the so-called $\boldsymbol{A} \boldsymbol{B D}$-matrix is given by

$$
[\boldsymbol{A}, \boldsymbol{B}, \boldsymbol{D}]=\sum_{k=1}^{n} \overline{\boldsymbol{Q}}_{k} \int_{z_{k}}^{z_{k+1}}\left[1, z, z^{2}\right] d z
$$

and where $\overline{\boldsymbol{Q}}_{k}=\boldsymbol{T}_{k} \boldsymbol{Q}_{k} \boldsymbol{T}_{k}^{T}$ is the stiffness matrix of the $k^{t h}$ lamina in the global coordinate system, $\boldsymbol{Q}_{k}$ is the lamina stiffness matrix as defined in Eq. (5.4), $z_{k}$ is the $z$-coordinate of the $k^{t h}$ lamina and $\boldsymbol{T}_{k}$ is the transformation matrix for the lamina stresses from the local to the global coordinate system. Solving Eq. (5.6) for $\bar{\varepsilon}_{0}$ and $\overline{\boldsymbol{\kappa}}$, and substituting into Eq. (5.5) gives the strains $\overline{\boldsymbol{\varepsilon}}$ over the laminate crosssection, which can be transformed to lamina strains $\varepsilon_{k}$ using $\boldsymbol{T}_{k}^{T}$ and to lamina stresses via Eq. (5.4) for each lamina.

The effects of hygrothermal expansion and can be included by adding the hygrothermal strain to the RHS of the second equation in Eq. (5.1)

$$
\varepsilon_{i j}^{H T}=\alpha_{i j} \Delta T+\beta_{i j} \Delta c
$$

where $\alpha_{i j}$ is the thermal expansion tensor, $\Delta T$ is the temperature change, $\beta_{i j}$ is the moisture expansion tensor and $\Delta c$ is the change in the moisture content. Further derivation to Eq. (5.6) is straight-forward.

When individual laminae are modelled using 3D solid finite elements, cf. Paper II and Paper III, the inverse of the matrix in Eq. (5.2) enters the element stiffness matrix. The laminate is then modelled by representing each lamina with one or more elements through the thickness. If the whole stack, or parts of it, are modelled 
using membrane (cf. Paper IV and Paper V), plate, shell (cf. Paper I and Paper II) or single solid elements, then the $\boldsymbol{A}, \boldsymbol{B}$ and $\boldsymbol{D}$ matrices are used in the element stiffness matrix. Irrespective of the modelling approach, the resulting quantities are the homogenized lamina strains and stresses, which can be evaluated against the failure criteria also given in homogenized quantities. However, in Paper IV and Paper V, the assumption is made that the fatigue failure takes place in the matrix and consequently the failure criterion is based on the homogenized matrix stresses $\boldsymbol{\sigma}_{m}$ within a ply. These are computed using the multi-continuum theory $[57,58]$, which is a micro-mechanics theory based on stress and strain averaging over each constituents representative volume. The following is obtained

$$
\boldsymbol{\sigma}_{m}=\phi_{m} \boldsymbol{Q}_{m}\left(\boldsymbol{Q}\left(\boldsymbol{I}-\left(\boldsymbol{Q}-\boldsymbol{Q}_{f}\right)^{-1}\left(\boldsymbol{Q}-\boldsymbol{Q}_{m}\right)\right)\right)^{-1} \boldsymbol{\sigma}
$$

where $\phi_{m}$ is the matrix volume fraction, and $\boldsymbol{Q}_{m}$ and $\boldsymbol{Q}_{f}$ are the matrix and fibre stiffness matrices, respectively. Equation (5.9) can be modified to include the effects of hygrothermal expansion, cf. Paper IV and [57, 58].

\subsection{Static failure}

In Chapter 3, the static failure of a laminate was described as a progressive failure event where the load is redistributed from the completely or partially failed layers to other layers which then might develop damage and fail. Such procedure can preferably be simulated by an iterative procedure where the load is increased incrementally and each layer is checked for damage in each increment. Once the damage has occurred in a layer, its stiffness properties are reduced and the loads are redistributed by consideration of equilibrium. The load is increased until all layers have completely failed and no residual stiffness remains. The point of failure initiation is specified by a suitable failure initiation criterion, a topic which is discussed in the next section.

\subsubsection{Failure initiation criteria}

A vast number of composite failure criteria has been introduced over the years, covering both intralaminar and interlaminar failure, where some of them are reviewed in [59]. An assessment and comparison of the predictive capabilities of a large number of existing intralaminar failure criteria was conducted in [60] in a World-Wide Failure Exercise (WWFE). Although some criteria performed better than others, no single criterion could accurately predict failure in all examined cases and some user recommendations were given [61]. A brief overview and discussion of different types of criteria is presented next. 
The failure criteria are commonly expressed in terms of homogenized lamina stresses or strains in the form

$$
F^{m}\left(\sigma_{i j}, \varepsilon_{i j}, \tilde{\sigma}_{i j}, \tilde{\varepsilon}_{i j}\right)=1
$$

where $\tilde{\sigma}_{i j}$ and $\tilde{\varepsilon}_{i j}$ symbolically denote the lamina strengths and failure strains respectively, and where $F^{m}$ denotes the failure initiation function of mode $m$.

\section{Limit criteria}

This is the simplest type of intralaminar criteria, where the failure initiation is assumed to occur when any of the lamina stress/strain components reaches its limit value. No interaction effects between the stress components are considered. The maximum stress criterion reads

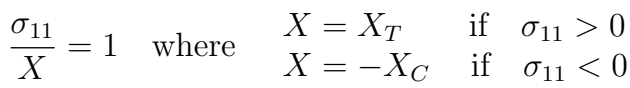

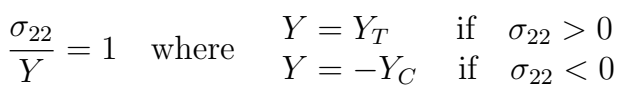

$$
\begin{aligned}
& \frac{\left|\sigma_{12}\right|}{S_{12}}=1
\end{aligned}
$$

where $X_{T}$ and $X_{C}$ are the lamina tensile and compressive strength in fibre direction, $Y_{T}$ and $Y_{C}$ are the tensile and compressive strength in transverse direction and $S_{12}$ is the shear strength.

\section{Polynomial criteria}

This type of criteria states a single scalar-valued function including all in-plane stress components

$$
F=F_{i j} \sigma_{i j}+G_{i j} \sigma_{i k} \sigma_{k j}+\ldots=1
$$

where $i, j=1,2$, and where $F_{i j}$ and $G_{i j}$ are material parameter tensors. One of the earliest intralaminar polynomial criteria, the Tsai-Hill criterion, was proposed 
by Azzi and Tsai [62] and was based on Hill's criterion [6] for ductile anisotropic metal sheets. It yields

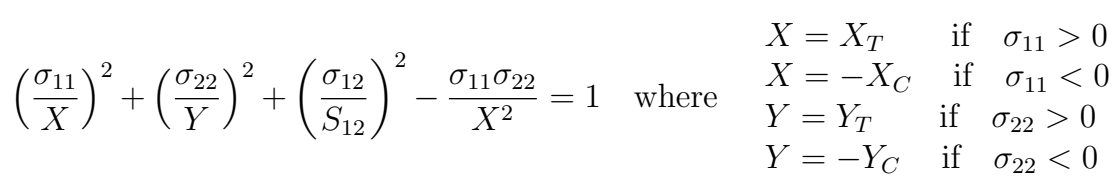

Although the criterion takes into account the interaction of the stress components it is based on the yielding mechanisms that take place in metals and not the diverse failure mechanisms associated with composites. Due to its lack of relevance for composites the Tsai-Hill criterion has been been the object of some criticism, for instance in $[63,64]$. Another well-known polynomial criterion, which suffers from the same drawback, is the Tsai-Wu criterion [65] which states that failure initiation occurs when

$$
\frac{\sigma_{11}^{2}}{X_{T} X_{C}}+\frac{\sigma_{22}^{2}}{Y_{T} Y_{C}}+\frac{\sigma_{12}^{2}}{S_{12}^{2}}-2 F_{12} \sigma_{11} \sigma_{22}+\left(\frac{1}{X_{T}}-\frac{1}{X_{C}}\right) \sigma_{11}+\left(\frac{1}{Y_{T}}-\frac{1}{Y_{C}}\right) \sigma_{22}=1
$$

The criterion requires, besides the five already mentioned strength constants, the interaction material parameter $F_{12}$, which is obtained by a biaxial load test.

Criteria based on physical considerations

The assessment of the physical failure process described in Chapter 3 implies that a failure criterion should include a distinction between the fibre dominated and the matrix dominated failure modes. Indeed, many different criteria have been derived based on the physical characteristics of the failure, and which accordingly incorporate this distinction. A widely used 2D criterion, known as the Hashin criterion was published in [66] and was later modified into a 3D form in [67], recognizes four distinct types of failure

Tensile fiber failure $\left(\sigma_{11}>0\right)$

$$
\left(\frac{\sigma_{11}}{X_{T}}\right)^{2}+\frac{1}{S_{12}^{2}}\left(\sigma_{12}^{2}+\sigma_{13}^{2}\right)=1
$$

Compressive fiber failure $\left(\sigma_{11}<0\right)$

$$
-\frac{\sigma_{11}}{X_{C}}=1
$$


Tensile matrix failure $\left(\sigma_{22}+\sigma_{33}>0\right)$

$$
\frac{1}{Y_{T}^{2}}\left(\sigma_{22}+\sigma_{33}\right)^{2}+\frac{1}{S_{23}^{2}}\left(\sigma_{23}^{2}-\sigma_{22} \sigma_{33}\right)+\frac{1}{S_{12}^{2}}\left(\sigma_{12}^{2}+\sigma_{13}^{2}\right)=1
$$

Compressive matrix failure $\left(\sigma_{22}+\sigma_{33}<0\right)$

$$
\frac{1}{Y_{C}}\left[\left(\frac{Y_{C}}{S_{23}}\right)^{2}-1\right]\left(\sigma_{22}+\sigma_{33}\right)+\frac{1}{4 S_{23}^{2}}\left(\sigma_{22}+\sigma_{33}\right)^{2}+\frac{1}{S_{23}^{2}}\left(\sigma_{23}^{2}-\sigma_{22} \sigma_{33}\right)+\frac{1}{S_{12}^{2}}\left(\sigma_{12}^{2}+\sigma_{13}^{2}\right)=1
$$

The 2D version of this criterion was used in Paper III. In between the two Hashin publications, Yamada and Sun [68] proposed a criterion suited for the fibre controlled laminates which is similar to the Tsai-Hill criterion if $\sigma_{22}=0$

$$
\left(\frac{\sigma_{11}}{X}\right)^{2}+\left(\frac{\sigma_{12}}{S_{i s}}\right)^{2}=1 \quad \text { where } \begin{array}{lll}
X=X_{T} & \text { if } & \sigma_{11}>0 \\
X=-X_{C} & \text { if } & \sigma_{11}<0
\end{array}
$$

where $S_{i s}$ is the in-situ lamina shear strength, determined from measurement in cross-ply laminates. Based on this expression, Chang and Chang [69] and Chang and Lessard [70], proposed another criterion, in which shear strain-stress nonlinearity [71] was included in form of a third-order polynomial. Further modifications, as including the out-of-plane stresses were introduced by Olmedo and Santiuste [72]. This criterion is used in Paper II of this thesis, in the context of FE-modelling of bolted joint failure using solid elements. It yields

Tensile fiber failure $\left(\sigma_{11}>0\right)$

$$
\sqrt{\left(\frac{\sigma_{11}}{X_{T}}\right)^{2}+\frac{\frac{\tau_{12}^{2}}{2 G_{12}}+\frac{3}{4} \alpha \tau_{12}^{4}}{\frac{S_{12}^{2}}{2 G_{12}}+\frac{3}{4} \alpha S_{12}^{4}}+\frac{\frac{\tau_{13}^{2}}{2 G_{13}}+\frac{3}{4} \alpha \tau_{13}^{4}}{\frac{S_{13}^{2}}{2 G_{13}}+\frac{3}{4} \alpha S_{13}^{4}}}=1
$$

Compressive fibre failure $\left(\sigma_{11}<0\right)$

$$
-\frac{\sigma_{11}}{X_{C}}=1
$$




\section{Matrix in-plane failure}

$$
\sqrt{\left(\frac{\sigma_{22}}{Y}\right)^{2}+\frac{\frac{\tau_{12}^{2}}{2 G_{12}}+\frac{3}{4} \alpha \tau_{12}^{4}}{\frac{S_{12}^{2}}{2 G_{12}}+\frac{3}{4} \alpha S_{12}^{4}}+\frac{\frac{\tau_{23}^{2}}{2 G_{23}}+\frac{3}{4} \alpha \tau_{23}^{4}}{\frac{S_{23}^{2}}{2 G_{23}}+\frac{3}{4} \alpha S_{23}^{4}}}=1 \quad \text { where } \quad \begin{array}{llll}
Y=Y_{T} & \text { if } & \sigma_{22}>0 \\
Y & =-Y_{C} & \text { if } & \sigma_{22}<0
\end{array}
$$

\section{Matrix out-of-plane failure}

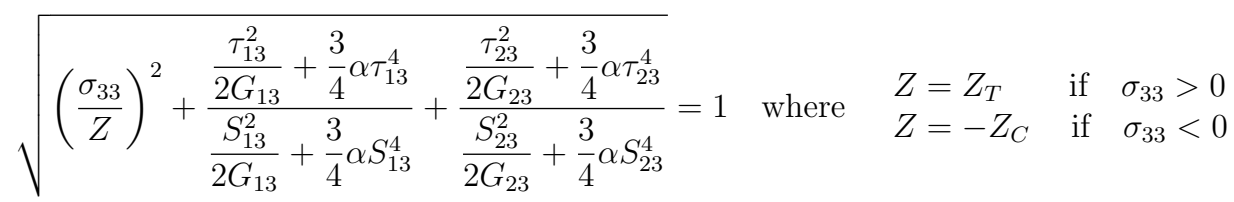

Fibre-matrix shearing failure $\left(\sigma_{11}<0\right)$

$$
\sqrt{\left(\frac{\sigma_{11}}{X_{C}}\right)^{2}+\frac{\frac{\tau_{12}^{2}}{2 G_{12}}+\frac{3}{4} \alpha \tau_{12}^{4}}{\frac{S_{12}^{2}}{2 G_{12}}+\frac{3}{4} \alpha S_{12}^{4}}+\frac{\frac{\tau_{13}^{2}}{2 G_{13}}+\frac{3}{4} \alpha \tau_{13}^{4}}{\frac{S_{13}^{2}}{2 G_{13}}+\frac{3}{4} \alpha S_{13}^{4}}}=1
$$

where $Z_{T}$ and $Z_{C}$ are the lamina tensile and compressive strength in the out-ofplane direction and where $\alpha$ is a fitting parameter.

More elaborate models were proposed by Puck and Schürmann in [24] and [73], where the angle of the matrix crack was considered and several matrix failure modes were identified. Further development of Puck's criterion was performed by Davila et al. in [74] involving critical planes for matrix cracks, fibre-matrix interaction in kinking failure and determination of in-situ strength of embedded plies using fracture mechanics. The latter was utilized in static failure modelling of bolted joints in Paper III. A 3D version of this criterion including shear non-linearity was developed in [75].

The review in [59], refers to a variety of different criteria for initiation of interlaminar failure and growth of delaminations. The majority of the initiation criteria are generally polynomial expressions containing out-of-plane normal and shear stresses and strengths, cf. Eq. (5.12). In Paper III delamination in the bolted joint was modelled using cohesive interface elements embedded between the plies and the delamination initiation was based on a quadratic traction criterion. 


\subsubsection{Damage progression}

After the failure has initiated, damage accumulation and energy dissipation take place until complete failure. During the damage progression stage, a significant loss of stiffness is observed. A common modelling approach, known as the ply-discount method, is to reduce the relevant lamina stiffness terms after the failure initiation criterion has been fulfilled. The stiffness terms are chosen depending on the failure mode, but the reduction level to which they are reduced is somewhat arbitrary. The approach has been implemented in bolted joint models in a number of studies [72, 76-80] and has also been used in Paper II.

Another approach, which has more physical relevance as well as a firm theoretical basis, is the continuum damage mechanics (CDM) approach [81]. Typically, the damage is not represented as a discrete entity, e.g. a crack, but as a distributed quantity related to a certain damage mechanism, and accounted for by a damage variable. When the failure initiation criterion is fulfilled, the damage variable activates and accumulates, according to a damage evolution law, with continued loading, until complete failure. The material exhibits a softening behaviour after failure initiation. A large number of CDM-models is published in the literature and some examples are found in [82-87]. The typical framework is based on the second law of thermodynamics, which is expressed through the Clausius-Duhem inequality [3], which at constant temperature can be written as

$$
\dot{G}-\dot{\sigma}_{i j} \varepsilon_{i j} \geq 0
$$

where $G=G\left(\sigma_{i j}, d_{m}\right)$ is the complementary energy and $d_{m}$ is the damage variable of mode $m$. Differentiation gives

$$
\left(\frac{\partial G}{\partial \sigma_{i j}}-\varepsilon_{i j}\right) \dot{\sigma}_{i j}+\frac{\partial G}{\partial d_{m}} \dot{d}_{m} \geq 0
$$

which must hold for arbitrary processes. As the dissipation is zero for processes without damage evolution, it follows that, for such situations, the expression in the parenthesis must equal zero, which with Eq. (5.1) gives

$$
\varepsilon_{i j}=\frac{\partial G}{\partial \sigma_{i j}}=S_{i j k l} \sigma_{k l}
$$

Assuming this relation to hold for all processes, one gets

$$
\frac{\partial G}{\partial d_{m}} \dot{d}_{m} \geq 0
$$


The expression in Eq. (5.20a) implies that the compliance tensor depends on the damage variables while the inequality in Eq. (5.20b) states that the energy dissipation due to the change of damage state cannot be negative. If the complementary energy has been chosen so that the thermo-dynamic forces $\partial G / \partial d_{m}$ are positive, the sufficient condition for fulfilment of the second law is that the rates of the damage variables are non-negative.

The damage is, in the classical sense of CDM, thought of as the loss of stress transmitting area. The remaining, undamaged area, is subjected to the effective stress $\widehat{\sigma}_{i j}$, which is related to the nominal stress through the damage operator $M_{i j k l}$ as

$$
\widehat{\sigma}_{i j}=M_{i j k l} \sigma_{k l}
$$

and to the strain through the undamaged compliance tensor $S_{i j k l}^{0}$, i.e. the compliance tensor for $d_{m}=0$, as

$$
\varepsilon_{i j}=S_{i j k l}^{0} \widehat{\sigma}_{k l}
$$

Combining Eq. (5.22) and (5.21) gives

$$
\varepsilon_{i j}=S_{i j k l}^{0} M_{k l m n} \sigma_{m n}
$$

which, when compared to Eq. (5.20a), gives the compliance tensor $S_{i j m n}=S_{i j k l}^{0} M_{k l m n}$.

The damage dependence of the compliance tensor, and thus also the stiffness tensor, is entirely controlled by the damage operator $M_{i j k l}$, which in turn is a function of the damage variables. An example of such a damage operator, using the Voigt notation, can be found in [85]

$$
\boldsymbol{M}=\left[\begin{array}{ccc}
\frac{1}{1-d_{f}} & 0 & 0 \\
0 & \frac{1}{1-d_{m}} & 0 \\
0 & 0 & \frac{1}{1-d_{s}}
\end{array}\right]
$$

where $d_{f}, d_{m}$ and $d_{s}$ are the damage variables related to fibre, matrix and shear damage, respectively. To complete the model, a damage evolution law is needed. 
It can be written directly, as in Paper III where the damage evolution is formulated such that linear softening, in terms of relevant strain and stress measures, is obtained. Another way to determine the damage rate is from a potential function, similar to the flow potential function in the plasticity theory, which depends on the hardening parameters and internal variables [3, 88].

Interlaminar damage progression is modelled in Paper III using cohesive interface elements [89], in which the damage is represented by a single scalar damage variable, expressed in terms of the relative displacement of the interfaces. The damage evolution law describes a linear softening traction-separation behaviour, similar to the one used in the intralaminar CDM-model.

\subsection{Fatigue failure}

There is a large variety of fatigue failure prediction models available in the literature [14-16, 90, 91], ranging from fatigue life models based on experimental data fitted to S-N type curves, to phenomenological models where empirically determined evolution laws control the degradation of the stiffness and strength, and progressive damage type models where a damage mechanism is represented by a damage variable which accumulates during the cyclic loading. Many of the models require a large number of material parameters which are only valid for the type of laminate and loading conditions that they were determined for. The damage accumulation at spectrum loading is, in most models, considered by an empirical damage accumulation law, similar to the Miner's rule for metals.

The fatigue failure prediction model implemented in this work, cf. Paper IV and Paper $\mathbf{V}$, is motivated by the experimental finding that the matrix cracking is the main driving mechanism for fatigue failure. Based on that, the kinetic theory of fracture for polymers [92-94] is adopted as the modelling framework and adapted for constant amplitude and spectrum loading. Similar work has previously been done for constant amplitude loading in [95-98]. The theory describes the matrix cracking as a thermally activated process, in which the rupture rate of atomic bonds, $K_{b}$, is increased by the presence of the cyclic homogenized matrix stress, Eq. (5.9). The rate of bond rupture is then

$$
\dot{N}=\left(N_{T}-N\right) K_{b}\left(\boldsymbol{\sigma}_{m}(t), T\right)
$$

where $N_{T}-N$ is the concentration of available weak points, $T$ is the absolute temperature and $t$ is the time. Integrating Eq. (5.25) over the matrix stress history results in a damage parameter expression. When the damage parameter reaches a critical value, a matrix crack is considered to be formed. The damage parameter expression includes the influence of the loading frequency, the temperature and the load ratio on the fatigue life, which greatly reduces the need for material 
characterization as only four parameters control the material behaviour. In Paper IV and Paper V, the model parameters were fitted to the data for un-notched specimens, loaded at constant amplitude at three different stress ratios. Using these parameters, it was possible to make reasonable predictions of the fatigue life of notched specimens and the composite plate in the bolted joints at uniaxial and biaxial, constant amplitude and spectrum loadings. The drawback of the model is that the hysteresis heating, due to the cyclic loading, has to be accounted for in order to achieve the correct model behaviour for different load ratios.

Interlaminar fatigue failure and material degradation due to cycling loading was not considered in this work. 


\section{Finite element modelling}

This chapter includes a brief summary of the FE-techniques used in this work to model the failure of composite in bolted joints: detailed modelling of quasistatic failure, simplified modelling of failure using structural line elements and modelling of fatigue failure. General theoretical background of the FEM-technique can be found in books like [99-101], while composite specific topics in are treated in e.g. $[88,102,103]$.

\subsection{Modelling of quasi-static failure}

A large number of FE-studies of bolted joints with composite plates exist in the literature [104]. They range from 2D models with rigid pins representing the bolt $[78,105,106]$, to 3D solid models with or without damage development in the composite $[47,52,72,76,80,103,107-111]$ and they include parameters such as bolt pretension, bolt clearance, the effect of countersunk/protruding bolt heads, different failure initiation and damage progression models, by-pass loading, implicit/explicit solution methods etc. This work includes solid models of countersunk single-lap joints, cf. Paper II, and a protruding head double-lap joint, cf. Paper III, which were created and analysed in the commercial software Abaqus [112]. Each ply in the composite plate is, in both cases, represented with one eight-node, reduced integration solid $3 \mathrm{D}$ element in the thickness direction.

The purpose of the modelling of the single-lap joints in Paper II was to derive their local force-displacement responses, which were then inserted as the characteristics of the structural line elements representing the fasteners in a global model of the wing box in Fig. 2. The damage progression in the composite was handled by a userdefined subroutine, utilizing the failure criterion in Eq. (5.17) and the ply-discount method with the sudden degradation of the stiffness parameters as in $[79,80]$. The solution was performed in small load increments by the standard Newton-Raphson algorithm, where the material subroutine was executed in each increment. Contact conditions, including friction with frictional coefficients from [113], were prescribed for all interfaces between the bolt and the plates. The predicted force-displacement response of the joint correlated well with experimental results from [30], although the maximum bearing load was somewhat over predicted. It was concluded that, despite the phenomenological nature of the sudden stiffness degradation in the ply- 
discount method, the models were useful for deriving the generic force-displacement response.

In Paper III, the aim of the modelling was to simulate the bearing failure process observed in the uniaxially and biaxially loaded test specimens. An intralaminar CDM-model with the Hashin failure criterion, Eq. (5.15), and linear stress-strain softening was implemented as a subroutine for this purpose. The failure strain was determined from experimentally obtained fracture energies related to each failure mode. Delaminations were modelled using cohesive elements embedded between each ply in the laminate. The solution was performed by an explicit time-stepping algorithm, which eliminated the contact convergence difficulties encountered in the implicit solution in Paper II. This approach gave physically more relevant results than the one in Paper II, as the influence of each of the main damage modes on the failure process was captured. Furthermore, the predicted failure load correlated well with the experimental results, for both uniaxially and biaxially loaded specimens.

\subsection{Structural modelling}

The modelling methods described in the previous section are computationally expensive and are therefore not suitable for modelling structures with many fasteners. Simplified methods have therefore been introduced by several authors, for instance Weyer et al. [114] used Abaqus connector elements to model self-piercing rivets, Gray and McCarhty connected beam elements to a cylindrical rigid surface to represent the bolt in [115] and implemented a user-defined element in [116], Ekh and Schön [117] used beam elements to represent the bolt and the laminates, and connector elements to account for the bolt-hole clearance and friction.

In Paper I and Paper II the bolts were represented by Abaqus connector elements, while the plates were modelled using conventional shell elements and continuum shell elements [118]. Connector elements impose a force-displacement constraint between two nodes, which can be defined by the user. In the conceptual study of the wing box, cf. Paper I, the connector elements were assigned a linear elastic stiffness and the models were used to determine the bolt load distribution. In Paper II, the force-displacement curves were derived from local models, described in the previous section, and assigned to the in-plane resultant of the connector elements. This method includes the effects of the composite damage and aluminium plasticity into the structural model in an efficient way. Furthermore, it was possible to remove individual fastener elements after they had failed, and thereby simulate the progressive failure of bolts within a bolt row. Assuming only linear force-displacement behaviour tends to over-predict the maximum bolt load in the structure and results in an incorrect bolt load distribution at high load levels. It was also found, that the thermally induced bolt loads were of significant magnitude. 


\subsection{Fatigue failure modelling}

The number of published FE-based studies of fatigue failure in composite bolted joints is small. Shokrieh and Lessard [119, 120] developed a phenomenological approach based on iterative degradation of the stiffness and residual strength and implemented it in an FE-based procedure. Close predictions of fatigue failure were attained for several pin-loaded laminates. Although the model works well, it requires a fair amount of material data in terms of stiffness and strength in different laminate directions.

In Paper IV and Paper V, the fatigue failure model described in Section 5.3 was implemented in a 2D FE-model of the bolted composite specimen. Both constant amplitude and variable amplitude loading were considered, in uniaxial and biaxial bearing load states. The FE-model was made of iso-parametric quadrilateral, eightnode plain stress elements, integrated with a full Gauss quadrature integration rule and with linear elastic orthotropic material behaviour. The bolt load was applied by enforcing a constraint relation on the nodes, along a semi-circle on the hole edge in the direction of the resultant bolt load. These nodes were only allowed to move on the edge of a circle, representing the bolt, whose centre was assigned a prescribed displacement. By this approach it was possible to avoid iterative contact modelling and to save computational time.

The numerical analysis procedure was broken down in several blocks, as shown schematically in Fig. 13. First, the finite element analyses were performed, where the displacements for load cases with the maximum applied mechanical cyclic load, $F_{\max }$, and the thermally induced load, $F_{t h}$ were calculated. From the displacement field vector, $\boldsymbol{u}$, the homogenised lamina stress vector, $\boldsymbol{\sigma}$, in each layer was computed using the classical laminate theory. In the next step, the multi-continuum theory was introduced to the to compute the homogenised matrix stress vector, $\boldsymbol{\sigma}_{m}$, cf. Eq. (5.9). In the last step the failure criterion is applied, by integration of the stress history in Eq. (5.25), to compute the fatigue life $N_{f}$.

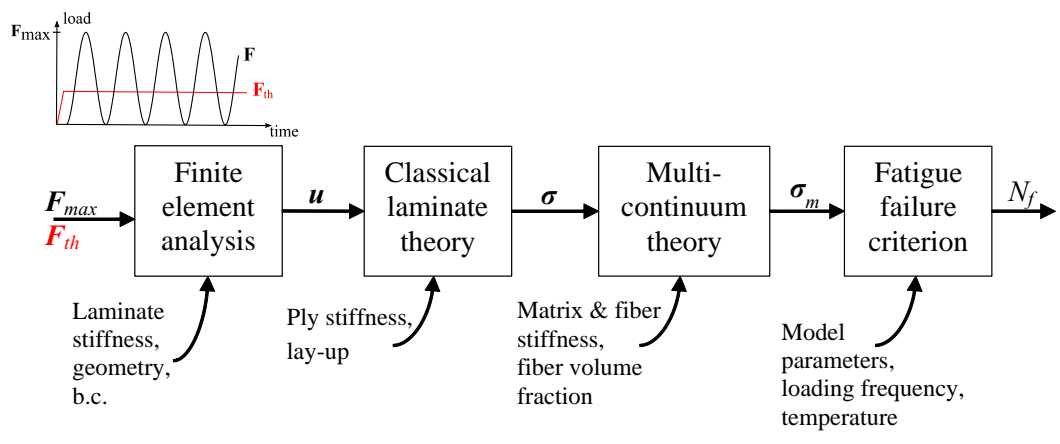

Figure 13. Flowchart of the computational procedure. 
The predictions of the fatigue life complied reasonably well with the experimental results for both constant and variable amplitude loading, although a large scatter was obtained in the experimental data. The simulated results helped in making a clear distinction between the results from the uniaxial and biaxial loading state in spectrum loading, which were otherwise clouded by the scatter.

The shortcoming of the model is that it predicts the failure in a single material point, whereas the experimental data refers to structural failure. This discrepancy was overcome with the help of the observation that the out-of-plane bending of the softened plies was restricted by the presence of the washer, which probably delayed the structural failure. Therefore, the prediction of the structural failure in the simulations was defined as failure of the first point outside the washer area. This seems to have worked well in this case. However, a general procedure for computation of structural fatigue life should include the effects of the material softening and the reduction of the residual strength. This could possibly be achieved by introduction of a relation between the increase of the damage variable and the reduction of the stiffness and strength parameters, but is for now considered as a possible future research topic. 


\section{Outlook}

The overall goal of this research is to develop efficient tools and methods which can be incorporated in the structural integrity assessment procedure and facilitate the certification process of hybrid aircraft structures. This requires an understanding of the local material phenomena but also efficient technical solutions that can incorporate the local material behaviour in large scale structures.

The local influence of the thermally induced loads on the composite failure has to some extent been evaluated, but the response of the aluminium part of the joint is yet to be studied. It is well-known that the fretting due to the contact condition at the bolt hole edge has a negative influence on the fatigue life of aluminium [27], but the influence of a cyclically applied biaxial bearing load state is not understood as well. Another issue is that the high peak loads are commonly eliminated from verification testing of metallic structure, since they may improve the fatigue life, while the opposite applies for composites. Up to now, the effects of single spectrum overloads on the composite fatigue life have not been considered in this work but are planned as a future topic of research. It is a straight forward matter to evaluate the significance of the overloads by the models presented in this thesis. If the overloads turn out to have a significant deleterious effect on the composite life, then the question arises how they should be accounted for in verification testing of hybrid structures without favouring the aluminium.

The modelling work on quasi-static failure has so far been related to the bearing failure mode only. A combination of bearing and by-pass load, and possibly including secondary bending, is however a more common situation and needs to be studied in order to further verify the predictive capability of the model. The same holds for the predictive capability of the fatigue model and the force-displacement relation in the structural line elements.

A large part of the remaining research project work is related to the testing of the wing box structure and evaluation of the associated results. The main focus will be directed towards identifying the critical failure mechanisms in different parts of the structure, and relating those to the results obtained from simulations. 



\section{Review of appended papers}

\section{Paper I}

Conceptual studies of a composite-aluminium hybrid wing box demonstrator

The paper presents a conceptual study of two different hybrid composite-aluminium designs of a wing box structure. The structure is designed given the thermal and mechanical loads and with respect to the strength, fatigue and stability requirements currently used in the aircraft industry. The overall structural response is evaluated, as well as the local and structural failure modes and the resulting masses of the two concepts are compared. Further, the requirements concerning allowable strains, allowable buckling load and given thermal loads are modified and another comparison is preformed between the two concepts for the new requirement set. The influence on the final mass is studied and one of the concepts is chosen to be used in a test.

\section{Paper II}

Finite element modelling of mechanically fastened composite-aluminium joints in aircraft structures

Detailed FE-modelling of structures including many fasteners tends to be computationally expensive. In this paper, a method is presented in which the local forcedisplacement response of a hybrid composite-aluminium joint is extracted from a detailed model and assigned to structural elements representing the fasteners in a global structural model. The local model includes progressive damage failure of the composite and metal plasticity. The method is demonstrated on a hybrid wing box structure exposed to thermal and mechanical loading, where the load distribution and the progressive fastener failure is studied. The initial joint stiffness predicted with the local models agreed well with the existing semi-empirical stiffness estimations. At a higher load level, the force-displacement curve deflects from linear 
due to the composite damage and aluminium plasticity. Simulations show that the fastener load distribution at high load levels is affected by this and that linear fastener models produce inaccurate results. The thermally induced fastener loads, due to the difference in the expansion properties of aluminium and composite, were considerable.

\section{Paper III}

\section{Quasi-static bearing failure of CFRP composite in biaxially loaded bolted joints}

This paper presents an experimental and numerical investigation of the quasi-static bearing failure of the composite in a hybrid bolted joint. The experiments were performed on two-bolt specimens at $90^{\circ} \mathrm{C}$ in uniaxial and biaxial loading. A specifically designed test rig was used to apply the biaxial load. The characteristics of the bearing failure were studied by an optical microscope and fibre kinking was identified as the main failure mechanism, although matrix cracking and delaminations were also observed. The experiments were simulated by the FE-analyses, where the intralaminar and interlaminar failure were included, and a good correlation to the experimental results was obtained. The same maximum resultant bearing load was seen in both the uniaxial and biaxial loading.

\section{Paper IV}

Fatigue bearing failure of CFRP composite in biaxially loaded bolted joints at elevated temperature

The same experimental setup and the same type of specimen as in Paper III were used for testing at constant amplitude loading. A microscopy study of the bearing plane surface showed a development of matrix cracks and fibre-matrix debonding, followed by ply fracture and delamination. A significant compliance increase was observed during the cycling, as a result of the damage progression. A fatigue life prediction model, based on matrix cracking as the driving failure mechanism, was implemented in an FE-program and used to simulate the test results. It was found that the biaxial loading resulted in a longer fatigue life than the uniaxial loading for the same resultant peak bolt load. The explanation was the smaller effective stress range in the biaxial case. 


\section{Paper V}

Fatigue bearing failure of CFRP composite in bolted joints exposed to biaxial variable amplitude loading at elevated temperature

Variable amplitude loading, with a standard wing bending spectrum was applied in the same test rig and to the same specimen type as in Paper III and Paper IV. The fatigue prediction model developed in Paper IV was modified to include the effects of the variable amplitude loading. Both the experiments and the simulations indicate, as in Paper IV, that the biaxial loading results in a longer fatigue life than the uniaxial loading for the same resultant maximum peak bolt load. However, large scatter was observed in the data. Predictions using Miner's accumulative damage rule turned out to give unconservative results. 



\section{Bibliography}

[1] MIL-STD-1530C. DoD Standard Practice, Aircraft Structural Integrity Program (ASIP). Aeronautical Systems Center, Wright-Patterson AFB, Ohio, 2005 .

[2] Whitehead RS. Lessons learned for composite structures. In The first NASA advanced composites technology conference, Part I, pages 399-415, Seattle, 1990.

[3] Ottosen NS and Ristinmaa M. The mechanics of constitutive modeling. Elsevier, Oxford, 2005.

[4] Lemaitre J and Chaboche JL. Mechanics of solid materials. Cambridge University Press, Cambridge, 1994.

[5] Lubliner J. Plasticity theory. Macmillan, New York, 1990.

[6] Hill R. The mathematical theory of plasticity. Oxford University Press, Oxford, 1950.

[7] Anderson TL. Fracture mechanics. CRC Press, Boca Raton, 2005.

[8] Gdoutos EE. Fracture mechanics, an introduction. Springer, Dordrecht, 2005 .

[9] Talreja R and Singh CV. Damage and failure of composite materials. Cambridge University Press, Cambridge, 2012.

[10] Vasiliev VV and Morozov EV. Mechanics and analysis of composite materials. Elsevier Science, Oxford, 2001.

[11] Daniel IM and Ishai O. Engineering mechanics of composite materials. Oxford University Press, Oxford, 1994.

[12] Jones RM. Mechanics of composite materials. McGraw Hill, New York, 1975.

[13] Kaw AK. Mechanics of composite materials. CRC Press, Boca Raton, 2006.

[14] Harris B. Fatigue in composites. Woodhead Publishing, Cambridge, 2003.

[15] Vassilopoulos AP and Keller T. Fatigue of fiber-reinforced composites. Springer, London, 2011. 
[16] Vassilopoulos AP. Fatigue life prediction of composites and composit structures. Woodhead Publishing, Cambridge, 2010.

[17] Defence Standard 00-970. Design and Airworthiness Requirements for Service Aircraft. 1 Fixed Wing Section 3 Structure. UK Ministry of Defence.

[18] Rouchon J. Fatigue and damage tolerance evaluation of structures: The composite material response. In 22th Plantema memorial lecture, 25th ICAF symposium, Rotterdam, 2009.

[19] MIL-HDBK-17-3F. Military handbook, polymer matrix composites. U.S. Department of Defense, 2000.

[20] Rouchon J. Certification of large airplane composite structures - Recent progress and new trends in compliance philosophy. In Proc. 17th ICAS Congress, Stockholm, 1990.

[21] Hodgkinson JM. Mechanical testing of advanced fibre composites. Woodhead Publishing, Cambridge, 2000.

[22] MMPDS-08. Metallic materials properties development and standardization (MMPDS). Federal Aviation Administration, 2013.

[23] Hull D and Clyne TW. An introduction to composite materials. Cambridge University Press, Cambridge, 1996.

[24] Puck A and Schürmann H. Failure analysis of frp laminates by means of physically based phenomenological models. Composites Science and Technology, 58(7):1045-1067, 1998.

[25] Camanho PP, Dávila CG, Pinho ST, Iannucci L, and Robinson P. Prediction of in situ strengths and matrix cracking in composites under transverse tension and in-plane shear. Composites Part A: Applied Science and Manufacturing, 37(2):165-176, 2006.

[26] Suresh S. Fatigue of materials. Cambridge University Press, Cambridge, 1998.

[27] Schijve J. Fatiue of structures and materials. Springer, Dordrecht, 2009.

[28] Tsai SW. Composites design. Think Composites, Dayton, 1988.

[29] Thoppul SD, Finegan J, and Gibson RF. Mechanics of mechanically fastened joints in polymer-matrix composite structures - A review. Composites Science and Technology, 69(3-4):301-329, 2009.

[30] Ireman T, Ranvik T, and Eriksson I. On damage development in mechanically fastened composite laminates. Composite Structures, 49(2):151-171, 2000.

[31] Starikov R and Schön J. Quasi-static behaviour of composite joints with protruding-head bolts. Composite Structures, 51(4):411-425, 2001. 
[32] Starikov R and Schön J. Quasi-static behaviour of composite joints with countersunk composite and metal fasteners. Composites Part B: Engineering, 32(5):401-411, 2001.

[33] Chishti M, Wang CH, Thomson RS, and Orifici AC. Experimental investigation of damage progression and strength of countersunk composite joints. Composite Structures, 94(3):865-873, 2012.

[34] Ekh J, Schön J, and Zenkert D. Simple and efficient prediction of bearing failure in single shear, composite lap joints. Composite Structures, 105:35-44, 2013.

[35] Xiao Y and Ishikawa T. Bearing strength and failure behavior of bolted composite joints (part I: Experimental investigation). Composites Science and Technology, 65(7-8):1022-1031, 2005.

[36] Starikov R and Schön J. Experimental study on fatigue resistance of composite joints with protruding-head bolts. Composite Structures, 55(1):1-11, 2002.

[37] Starikov R and Schön J. Local fatigue behaviour of CFRP bolted joints. Composites Science and Technology, 62(2):243-253, 2002.

[38] Schön J and Nyman T. Spectrum fatigue of composite bolted joints. International Journal of Fatigue, 24(2-4):273-279, 2002.

[39] Smith PA and Pascoe KJ. Fatigue of bolted joints in (0/90) CFRP laminates. Composites Science and Technology, 29(1):45-69, 1987.

[40] Seike S, Takao Y, Wang W-X, and Matsubara T. Bearing damage evolution of a pinned joint in CFRP laminates under repeated tensile loading. International Journal of Fatigue, 32(1):72-81, 2010.

[41] Counts WA and Johnson WS. Bolt bearing fatigue of polymer matrix composites at elevated temperature. International Journal of Fatigue, 24(24):197-204, 2002.

[42] Saunders DS, Galea SC, and Deirmendjian GK. The development of fatigue damage around fastener holes in thick graphite/epoxy composite laminates. Composites, 24(4):309-321, 1993.

[43] Persson E and Eriksson I. Fatigue of multiple-row bolted joints in carbon/epoxy laminates: ranking of factors affecting strength and fatigue life. International Journal of Fatigue, 21(4):337-353, 1999.

[44] Graham U, Wisnom MR, and Webber JPH. A novel finite element investigation of the effects of washer friction in composite plates with bolt-filled holes. Composite Structures, 29(3):329-339, 1994. 
[45] Ekh J and Schön J. Effect of secondary bending on strength prediction of composite, single shear lap joints. Composites Science and Technology, 65:953-965, 2005.

[46] Ekh J, Schön J, and Melin LG. Secondary bending in multi fastener, compositealuminium single shear lap joints. Composites Part B: Engineering, 36(3):195208, 2005 .

[47] Rosales-Iriarte F, Fellows NA, and Durodola JF. Failure prediction in carbon composites subjected to bearing versus bypass loading. Journal of Composite Materials, 46(15):1859-1878, 2012.

[48] Egan B, McCarthy CT, McCarthy MA, and Frizzell RM. Stress analysis of single-bolt, single-lap, countersunk composite joints with variable bolt-hole clearance. Composite Structures, 94(3):1038-1051, 2012.

[49] Starikov R and Schön J. Fatigue resistance of composite joints with countersunk composite and metal fasteners. International Journal of Fatigue, 24(1):39-47, 2002.

[50] Ekh J and Schön J. Load transfer in multirow, single shear, composite-toaluminium lap joints. Composites Science and Technology, 66(7-8):875-885, 2006 .

[51] McCarthy CT and Gray PJ. An analytical model for the prediction of load distribution in highly torqued multi-bolt composite joints. Composite Structures, 93(2):287-298, 2011.

[52] McCarthy CT, McCarthy MA, and Lawlor VP. Progressive damage analysis of multi-bolt composite joints with variable bolt-hole clearances. Composites Part B: Engineering, 36(4):290-305, 2005.

[53] Zhou Y, Yazdani-Nezhad H, McCarthy MA, Wan X, and McCarthy C. A study of intra-laminar damage in double-lap, multi-bolt, composite joints with variable clearance using continuum damage mechanics. Composite Structures, 116:441-452, 2014.

[54] Kelly G and Hallström S. Bearing strength of carbon fibre/epoxy laminates: effects of bolt-hole clearance. Composites Part B: Engineering, 35(4):331343, 2004.

[55] FALSTAFF. Description of a fighter aircraft loading standard for fatigue. Joint publication of Flugzeugwerke Emmen $(\mathrm{F}+\mathrm{W})$, Switzerland, Laboratorium für Betriebsfestigkeit (LBF), Darmstadt, Germany, National Aerospace Laboratory (NLR), Amsterdam, Netherlands, and Industrie - Anlagen - Betriebsgesellschaft mbH (IABG), Ottobrunn, Germany, 1976.

[56] Reddy JN. Mechanics of laminated composite plates and shells: theory and analysis. CRC Press, Boca Raton, 2004. 
[57] Hansen AC and Garnich MR. A multicontinuum theory for structural analysis of composite material systems. Composites Engineering, 5(9):1091-1103, 1995 .

[58] Mayes JS and Hansen AC. Composite laminate failure analysis using multicontinuum theory. Composites Science and Technology, 64(3-4):379-394, 2004 .

[59] Orifici AC, Herszberg I, and Thomson RS. Review of methodologies for composite material modelling incorporating failure. Composite Structures, 86(1-3):194-210, 2008.

[60] Hinton MJ, Kaddour AS, and Soden PD. Failure criteria in fibre-reinforced polymer composites: the world-wide failure exercise. Elsevier, Amsterdam, 2004.

[61] Soden PD, Kaddour AS, and Hinton MJ. Recommendations for designers and researchers resulting from the worl-wide failure exercise. Composites Science and Technology, 64:589-604, 2004.

[62] Azzi VD and Tsai SW. Anisotropic strength of composites. Experimental Mechanics, 5(9):283-288, 1965.

[63] Hart-Smith LJ. The role of biaxial stresses in discriminating between meaningful and illusory composite failure theorie. McDonnell Douglas Corporation, Long Beach, 1991.

[64] Talreja R. Assessment of the fundamentals of failure theories for composite materials. Composites Science and Technology, 105:109-201, 2014.

[65] Tsai SW and Wu EM. General theory of strength for anisotropic materials. Journal of Composite Materials, 5:58-80, 1971.

[66] Hashin $\mathrm{Z}$ and Rotem A. A fatigue failure criterion for fiber reinforced materials. Journal of Composite Materials, 7:448-464, 1973.

[67] Hashin Z. Failure criteria for unidirectional fibre composites. Journal of Applied Mechanics, 47:329-334, 1980.

[68] Yamada SE and Sun CT. Analysis of laminate strength and its distribution. Journal of Composite Materials, 12:275-284, 1978.

[69] Chang FK and Chang KY. A progressive damage model for laminated composites containing stress concentrations. Journal of Composite Materials, 21(9):834-855, 1987.

[70] Chang FK and Lessard LB. Damage tolerance of laminated composites containing an open hole and subject to compressive loadings: part I - analysis. Journal of Composite Materials, 25(1):2-43, 1991.

[71] Hahn HT and Tsai SW. Nonlinear elastic behavior of unidirectional composite laminates. Journal of Composite Materials, 7(1):102-118, 1973. 
[72] Olmedo A and Santiuste C. On the prediction of bolted single-lap composite joints. Composite Structures, 94(6):2110-2117, 2012.

[73] Puck A and Schürmann H. Failure analysis of frp laminates by means of physically based phenomenological models. Composites Science and Technology, 62(12-13):1633-1662, 2002.

[74] Davila CG, Camanho PP, and Rose CA. Failure criteria for FRP laminates. Journal of Composite Materials, 39(4):323-345, 2005.

[75] Pinho ST, Dávila CG, Camnho PP, Iannucci L, and Robinson P. Failure modelsand criteria for FRP under in-plane or three-dimensional stress states including shear non-linearity. Technical report, NASA/TM-2005-213530, 2005 .

[76] Zhang J and Rowland J. Damage modeling of carbon-fiber reinforced polymer composite pin-joints at extreme temperatures. Composite Structures, 94(8):2314-2325, 2012.

[77] Tserpes KI, Labeas G, Papanikos P, and Kermanidis Th. Strength prediction of bolted joints in graphite/epoxy composite laminates. Composites Part B: Engineering, 33:521-529, 2002.

[78] Dano ML, Kamal E, and Gendron G. Analysis of bolted joints in composite laminates: Strains and bearing stiffness predictions. Composite Structures, $79(4): 562-570,2007$.

[79] Tan SC. A progressive failure model for composite laminates containing openings. Journal of Composite Materials, 25(5):556-577, 1991.

[80] Camanho PP and Mattews FL. A progressive damage model for mechanically fastened joints in composite laminates. Journal of Composite Materials, 33(4):2248-2280, 1999.

[81] Liu PF and Zheng JY. Recent developments on damage modeling and finite element analysis for composite laminates: a review. Materials and Design, 31:3825-3834, 2010.

[82] Matzenmiller A, Lubliner J, and Taylor RL. A constitutive model for anisotropic damage in fiber-composites. Mechanics of Materials, 20(2):125-152, 1995.

[83] Maimi P, Camanho PP, Mayugo JA, and Davila CG. A continuum damage model for composite laminates: Part I - constitutive model. Mechanics of Materials, 39(10):897-908, 2007.

[84] Maimi P, Camanho PP, Mayugo JA, and Davila CG. A continuum damage model for composite laminates: Part II - computational implementation and validation. Mechanics of Materials, 39(10):909-919, 2007. 
[85] Lapczyk I and Hurtado JA. Progressive damage modeling in fiber-reinforced materials. Composites Part A: Applied Science and Manufacturing, 38(11): 2333-2341, 2007.

[86] Pinho ST, Iannucci L, and Robinson P. Physically-based failure models and criteria for laminated fibre-reinforced composites with emphasis on fibre kinking: Part I: Development. Composites Part A: Applied Science and Manufacturing, 37(1):63-73, 2006.

[87] Pinho ST, Iannucci L, and Robinson P. Physically-based failure models and criteria for laminated fibre-reinforced composites with emphasis on fibre kinking: Part II: FE implementation. Composites Part A: Applied Science and Manufacturing, 37(5):766-777, 2006.

[88] Barbero EJ. Finite element analysis of composite materials using Abaqus. CRC Press, Boca Raton, 2013.

[89] Camanho PP, Davila CG, and de Moura MF. Numerical simulation of mixedmode progressive delamination in composite materials. Journal of Composite Materials, 37(16):1415-1438, 2003.

[90] Wicaksono S and Chai GB. A review of advances in fatigue and life prediction of fiber-reinforced composites. Proceedings of the Institution of Mechanical Engineers Part L: Journal of Materials Design and Applications, 227(3):179$195,2012$.

[91] Post NL, Case SW, and Lesko JJ. Modeling the variable amplitude fatigue of composite materials: A review and evaluation of the state of the art for spectrum loading. International Journal of Fatigue, 30(12):2064-2086, 2008.

[92] Zhurkov SN and Kuksenko VS. The micromechanics of polymer fracture. International Journal of Fracture, 11(4):629-639, 1975.

[93] Zhurkov SN. Kinetic concept of the strength of solids. International Journal of Fracture, 26(4):295-307, 1984.

[94] Hansen AC and Baker-Jarvis J. A rate dependent kinetic theory of fracture for polymers. International Journal of Fracture, 44(3):221-231, 1990.

[95] Fertig RS and Kenik DJ. Physics-based fatigue life prediction of composite structures. In NAFEMS World Congress, Boston, MA, 2011.

[96] Fertig RS and Kenik DJ. Predicting composite fatigue life using constituentlevel physics. In 52nd AIAA/ASME/ASCE/AHS/ASC Structures, Structural Dynamics and Materials Conference, Denver, CO, 2011.

[97] Fertig RS. Bridging the gap between physics and large-scale structural analysis: A novel method for fatigue life prediction of composites. In SAMPE Fall Technical Conference Proceedings: Global Material Technology: Soaring to New Horizons, Wichita, KS, 2009. 
[98] Mishnaevsky Jr. L and Brøndsted P. Modeling of fatigue damage evolution on the basis of the kinetic concept of strength. International Journal of Fracture, 144(3):149-158, 2007.

[99] Cook RD, Malkus DS, Plesha ME, and Witt RJ. Concepts and applications of finite element analysis. John Wiley, Hoboken, 2002.

[100] Huges TJR. The finite element method: linear static and dynamic finite element analysis. Dover Publications, New York, 2000.

[101] Belytschko T, Liu WK, and Moran B. Nonlinear finite elements for continua and structures. Wiley, Chichester, 2000.

[102] Matthews FL, Davies GAO, Hitchings D, and Soutis C. Finite element modelling of composite materials and structures. Woodhead Publishing, Cambridge, 2000.

[103] Ochoa OO and Reddy JN. Finite element analysis of composite laminates. Kluwer Academic Publishers, Waterloo, 1992.

[104] Camanho PP and Matthews FL. Stress analysis and strength prediction of mechanically fastened joints in FRP: a review. Composites Part A: Applied Science and Manufacturing, 28(6):529-547, 1997.

[105] Dano ML, Gendron G, and Picard A. Stress and failure of mechanically fastened joints in composite laminates. Composite Structures, 50(3):287$296,2000$.

[106] Xiao Y and Ishikawa T. Bearing strength and failure behavior of bolted composite joints (part II: modeling and simulation). Composites Science and Technology, 65(7-8):1032-1043, 2005.

[107] Hühne C, Zerbst AK, Kuhlmann G, Steenbock C, and Rolfes R. Progressive damage analysis of composite bolted joints with liquid shim layers using constant and continuous degradation models. Composite Structures, 92(2):189$200,2010$.

[108] Linde P, Pleitner J, De Boer H, and Carmone C. Modelling and simulation of fiber metal laminates. In ABAQUS Users Conference, 2004.

[109] Ireman T. Three-dimensional stress analysis of bolted single-lap composite joints. Composite Structures, 43(3):195-216, 1998.

[110] Egan B, McCarthy CT, McCarthy MA, Gray PJ, and Frizzell RM. Modelling a single-bolt countersunk composite joint using implicit and explicit finite element analysis. Computational Materials Science, 64:203-208, 2012.

[111] Chishti M, Wang CH, Thomson RS, and Orifici AC. Numerical analysis of damage progression and strength of countersunk composite joints. Composite Structures, 94(2):643-653, 2012. 
[112] Abaqus-Inc. Abaqus User Manual, Version 6.13. Technical report, Dassault Systèmes Simulia Corp. Providence, RI, USA, 2013.

[113] Schön J. Coefficient of friction for aluminum in contact with carbon fiber epoxy composite. Tribology International, 37(5):395-404, 2004.

[114] Weyer S, Hooputra H, and Zhou F. Modeling of self-piercing rivets using fasteners in crash analysis. In ABAQUS Users Conference, 2006.

[115] Gray PJ and McCarthy CT. A global bolted joint model for finite element analysis of load distributions in multi-bolt composite joints. Composites Part B: Engineering, 41(4):317-325, 2010.

[116] Gray PJ and McCarthy CT. A highly efficient user-defined finite element for load distribution analysis of large-scale bolted composite structures. Composites Science and Technology, 71(12):1517-1527, 2011.

[117] Ekh J and Schön J. Finite element modeling and optimization of load transfer in multi-fastener joints using structural elements. Composites Science and Technology, 82(2):245-256, 2008.

[118] de Borst R, Chrisfield MA, Remmers JJC, and Verhoosel CV. Non-linear finite element analysis of solids and structures. John Wiley, Chichester, 2012 .

[119] Shokrieh MM and Lessard LB. Progressive fatigue damage modeling of composite materials, Part I: Modeling. Journal of Composite Materials, 34(13):1056-1080, 2000.

[120] Shokrieh MM and Lessard LB. Progressive fatigue damage modeling of composite materials, Part II: Material characterization and model verification. Journal of Composite Materials, 34(13):1081-1116, 2000. 



\title{
Part II
}

\author{
Appended papers
}





\section{Papers}

The articles associated with this thesis have been removed for copyright reasons. For more details about these see:

http://urn.kb.se/resolve?urn=urn:nbn:se:liu:diva-122349 